\title{
Radiotheranostics - Precision Medicine in Nuclear Medicine and Molecular Imaging
}

\author{
Heying Duan, Andrei Iagaru, Carina Mari Aparici ${ }^{\bowtie}$ \\ Department of Radiology, Division of Nuclear Medicine and Molecular Imaging, Stanford University, Stanford, CA, USA \\ $\triangle$ Corresponding author: Heying Duan, MD. Department of Radiology, Division of Nuclear Medicine and Molecular Imaging, Stanford University, 300 Pasteur \\ Drive, H2200, Stanford, CA 94305, USA. Phone: +1 650725 4711; Fax: +1 650498 5047. heying@stanford.edu \\ (C) The author(s). This is an open access article distributed under the terms of the Creative Commons Attribution License (https://creativecommons.org/licenses/by/4.0/). \\ See http://ivyspring.com/terms for full terms and conditions.
}

Received: 2021.06.21; Accepted: 2021.08.09; Published: 2022.01.01

\begin{abstract}
'See what you treat and treat what you see, at a molecular level', could be the motto of theranostics. The concept implies diagnosis (imaging) and treatment of cells (usually cancer) using the same molecule, thus guaranteeing a targeted cytotoxic approach of the imaged tumor cells while sparing healthy tissues. As the brilliant late Sam Gambhir would say, the imaging agent acts like a 'molecular spy' and reveals where the tumoral cells are located and the extent of disease burden (diagnosis). For treatment, the same 'molecular spy' docks to the same tumor cells, this time delivering cytotoxic doses of radiation (treatment). This duality represents the concept of a 'theranostic pair', which follows the scope and fundamental principles of targeted precision and personalized medicine.

Although the term theranostic was noted in medical literature in the early 2000 s, the principle is not at all new to nuclear medicine. The first example of theranostic dates back to 1941 when Dr. Saul Hertz first applied radioiodine for radionuclide treatment of thyroid cells in patients with hyperthyroidism. Ever since, theranostics has been an integral element of nuclear medicine and molecular imaging. The more we understand tumor biology and molecular pathology of carcinogenesis, including specific mutations and receptor expression profiles, the more specific these 'molecular spies' can be developed for diagnostic molecular imaging and subsequent radionuclide targeted therapy (radiotheranostics). The appropriate selection of the diagnostic and therapeutic radionuclide for the 'theranostic pair' is critical and takes into account not only the type of cytotoxic radiation emission, but also the linear energy transfer (LET), and the physical half-lives. Advances in radiochemistry and radiopharmacy with new radiolabeling techniques and chelators are revolutionizing the field. The landscape of cytotoxic systemic radionuclide treatments has dramatically expanded through the past decades thanks to all these advancements. This article discusses present and promising future theranostic applications for various types of diseases such as thyroid disorders, neuroendocrine tumors (NET), pediatric malignancies, and prostate cancer (PC), and provides an outlook for future perspectives.
\end{abstract}

\section{Introduction}

The term theranostic became increasingly popular since the early 2000s and its publications have been rapidly increasing ever since. Theranostic is a portmanteau of the Greek words therapo and gnosis, translating to therapy and knowing, i.e., diagnostics [1, 2]. There is a constant debate whether 'theranostics' or 'theragnostics' should be used, however both spellings are acknowledged. The principle of theranostic is to identify the right molecular probe (diagnostic/therapeutic) for the right patient in order to maximize subsequent treatment outcome while minimizing toxicity. It stratifies upfront future responders from non-responders, hence preventing unnecessary treatments, sparing patients from the usual trial and error approach, and saving unnecessary drug costs for the healthcare system. The theranostic concept applies to many different areas of science depending on the platform used to convey the main principle. In that sense, theranostics could be further categorized as: radiotheranostic, nanotheranostic, magnetotheranostic and optotheranostic, by using radionuclides, nanoparticles, magnetic particles 
and optical probes, respectively [3,4]. Out of all the possible categories, radiotheranostic has been so far the only one widely adopted and integrated clinically, and therefore commonly referred to as theranostics. Radiotheranostics uses low penetration radiation emitted from radionuclides to deposit high levels of energy in the nucleus of the targeted cells to induce DNA strand breaks and activate programmed cell death. The concept of radiotheranostics has been clinically adopted for over 80 years now. Among the earliest examples of theranostic is the use of Phosphorus-32 (32P) for leukemia in 1941 [5], and Iodine-131 (131I) for Graves' disease published by Saul Hertz in 1942 [6], and subsequently thyroid cancer in 1946 [7]. Radioiodine therapies became one of the cornerstone treatments in nuclear medicine and is markedly used every day worldwide. Radiotheranostic complies with the ultimate concept of personalized medicine by using paired diagnostic/therapeutic radionuclide probes for the selective and targeted diagnosis and treatment of specific (usually cancer) cells, tailored to the patient's specific underlying disease. These theranostic probes allow for molecular characterization of cells and cancer cells in vivo, i.e., within the whole body, early detection of disease, disease staging, assessment of tumoral molecular heterogeneity by imaging, therapy selection, treatment planning, and subsequent targeted and tailored treatment based on the diagnostic molecular imaging results. The diagnostic part further allows for early assessment of treatment response and detection of recurrence, long before there are measurable anatomical changes, and plays a critical role in the differentiation between progression and pseudoprogression. The use of dosimetry to predict and determine the specific radiation absorbed doses by the tumor, organs at risk, and healthy tissues of every individual patient ensures the desired goals of efficacy and safety of the treatment. Advances in dosimetric software like voxel-based dosimetry will make dosimetry-guided targeted radionuclide therapies (TRT) more feasible. In pursuing a more personalized medicine, radiotheranostic is slowly moving from a fixed schedule of treatment cycles and dose activity to a more individualized approach based on the patient's specific tumor burden, biology, and dosimetry, which will allow immediate adjustment for toxicity and individualized decision making.

\section{Radiotheranostic Pairs}

A radiopharmaceutical consists of three components: the radionuclide (with diagnostic and/or therapeutic properties), a chelator (which links the radionuclide to the ligand/probe), and the ligand/probe (which targets a cancer-specific molecular marker on the tumor cell with high affinity). Sometimes, a radionuclide by itself can serve as a radiopharmaceutical without the need for a chelator or radiolabeling. The purest concept of a 'theranostic pair' consists of a chemically and structurally identical (or nearly identical) probe labeled with either a diagnostic or therapeutic radionuclide. This ensures targeting of the same molecular marker for diagnostic imaging and molecular targeted treatment. Radiolabeling is a critical step in the synthesis of a radiopharmaceutical since the receptor binding affinities may be negatively affected by a decreasing degree of similarity between the diagnostic and therapeutic molecule. In that sense, the 'perfect' theranostic pair would be two isotopes of the same element. The prime example is radioiodine, where for instance ${ }^{123} \mathrm{I}$ (single photon emitter) or ${ }^{124} \mathrm{I}$ (positron emitter) can be used for diagnostics and 131I (beta emitter) for treatment of thyroid diseases. These isotopes are chemically 'identical', and only differ in their emissions and physical half-lives, which is favorable for their respective purposes.

The diagnostic counterpart can be performed by employing either single photon emission computed tomography/computed tomography (SPECT/CT) or more commonly used positron emission tomography either with computed tomography (PET/CT) or magnetic resonance imaging (PET/MRI) to obtain molecular diagnostic images. The chosen radiopharmaceutical is either a gamma emitter for SPECT or a positron emitter for PET. Both gamma and positron emitting radiopharmaceuticals have high tissue absorption, a low energy transfer and a long radiation range, resulting in low-level radiation exposure for the patient with optimal imaging condition. In contrast to anatomical imaging like CT or MRI, molecular imaging visualizes tumor molecules and characterizes tumor tissue, function, and biology. This allows not only for disease localization, staging and restaging, but also, and a unique feature of theranostic, the ability to effectively select patients for subsequent TRT based on their chances to have a positive response to therapy. Molecular imaging determines whether there is sufficient expression of the molecular target based on tumor uptake compared to normal tissue and background uptake, and therefore whether the patient will benefit from TRT. This principle indicates that treatment with the same compound will be delivering a tumoricidal radiation dose to the cancer cells.

TRT is a systemic cytotoxic treatment which is applied either intravenously or orally. The ionizing radiation aims directly at the cancer-specific target and induces deoxyribonucleic acid (DNA) doublestrand breaks and subsequently organized cell death 
through apoptosis. Therefore, choosing the most appropriate radionuclide is key. The higher the linear energy transfer (LET) to the target cell, the higher the damage to the target cell and treatment efficacy. Also, the longer the emission range, which is the tissue penetration range, the larger the perimeter of the irradiated tissue area/treated area (measured in microns up to $2 \mathrm{~mm}$ ). Preferably, a radionuclide with a relatively long half-life (days to 1-2 weeks) is chosen to prolong the therapeutic effect. The most commonly used radioemitters in the clinic are beta particles like ${ }^{131} \mathrm{I}$, Lutetium-177 $\left({ }^{177} \mathrm{Lu}\right)$, Samarium-153 (153Sm), and Yttrium-90 ( $\left.{ }^{90} \mathrm{Y}\right)$. They are characterized by a high energy transfer to the tumor cell and a short radiation emission range, which is favorable to spare surrounding healthy tissue cells. Treatment with alpha particles like Radium-223 ${ }^{223} \mathrm{Ra}$ ) has been approved by the US Food and Drug Administration (FDA), others like Actinium-225 $(225 \mathrm{Ac})$ are being actively researched in human clinical trials. Compared to beta emitters, they are distinguished by a very high LET and an even shorter path length in the dimension of microns $(<100 \mu \mathrm{m})$. Another group of emitters that have been used in the past for theranostics are Auger electron emitters. However, these radionuclides are generally less effective as they provide very low energy electrons that decay by electron capture. The energy is deposited over a very short distance, so they become most effective strictly intracellularly. Examples of Auger electron emitters are ${ }^{123}$ I, Indium-111 (111In),

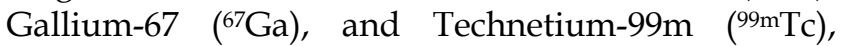
which are currently used for SPECT/CT at very low diagnostic doses, but some of them like ${ }^{123}$ I and ${ }^{111} \mathrm{In}$ have been introduced in clinical trials at high doses for treatment of thyroid diseases and neuroendocrine tumors (NET), respectively [8].

In addition, radionuclides usually have two or more types of emission with different energy peaks. This characteristic makes certain radioisotopes used for therapy to be suitable for non-diagnostic imaging. This non-diagnostic imaging can be of great utility to obtain post-treatment SPECT/CT imaging to confirm molecular targeting of the treatment, rule out pharmacologic interference and stunning. This is usually the case with beta emitters, which tend to have a certain abundance of gamma emission suitable for post-treatment imaging with SPECT/CT. These scans can also be used for dosimetry to determine the absorbed doses of the tumor(s) and healthy tissues.

\section{Thyroid Diseases - Radioiodine and Beyond}

Thyroid cancer is the most prevalent endocrine malignancy, and the incidence of papillary thyroid carcinoma (PTC) has increased over the past few decades due to improved diagnosis [9]. The American Cancer Society estimates 44,280 new cases of thyroid cancer in 2021 in the United States [10]. Differentiated thyroid cancer (DTC) accounts for the vast majority of thyroid cancers. They arise from follicular epithelial cells and are divided in PTC (85\%), follicular thyroid cancer including conventional (5\%) and oncocytic (Hürthle cell) carcinomas (5\%), poorly differentiated $(<3 \%)$ and anaplastic thyroid cancer $(<3 \%)$ [11].

Radioiodine treatment utilizes the underlying thyroid physiology of using iodide to synthesize thyroid hormones. Iodide is taken up from the blood stream by follicular thyroid cells through the sodium-iodide symporter (NIS) localized in the basolateral membrane. The NIS cotransports two sodium ions along with one iodide ion into the cytosol whereas the sodium gradient serves as driving force [12]. The efflux of iodide across the apical membrane into the follicular lumen is mediated by pendrin channels [13]. Thyroid peroxidase organifies iodide by oxidation and attachment to thyroglobulin. Iodinated thyroglobulin re-enters the follicular cell via endocytosis, undergoes hydrolysis, and the thyroid hormones T3 and T4 are subsequently secreted into the blood stream at the basolateral membrane [14]. Radioiodine is taken up and trapped in the thyroid cell in the same manner as any other iodine molecule. The thyroid cell cannot differentiate between the structurally identical radioactive and non-radioactive molecule. Several members of the radioiodine family are used for diagnostic or therapeutic purposes for hyperthyroidism and differentiated thyroid carcinoma (Table 1).

From a diagnostic point of view, SPECT imaging with ${ }^{123}$ I can be used for diagnosis and planning of radioiodine therapy in cases of DTC, hyperthyroidism like Graves' disease and toxic uni- or multinodular adenomas. PET imaging with ${ }^{124} \mathrm{I}$ is also a great diagnostic agent, although not as easily accessible as ${ }^{123}$ I. ${ }^{124} \mathrm{I}$ is used for staging and restaging of DTC, although its long half-life of 4 days makes it an excellent theranostic pair for dosimetry. Currently, the doses of radioiodine prescribed for radioiodine treatment of DTC are based on disease risk, disease burden and location of metastatic disease. This can lead to under- or overtreatment with subsequent adverse effects. Lesional dosimetry aids in moving towards an individualized treatment approach in order to maximize outcome and minimize toxicity. The feasibility of dosimetry with ${ }^{124} \mathrm{I}$ in predicting and estimating absorbed doses of individual tumor lesions is currently evaluated in various institutions in the United States and Germany (ClinicalTrials.gov identifiers NCT03647358, NCT03841617 and NCT01704586). 
Table 1: Examples of theranostic pairs currently in use.

\begin{tabular}{|c|c|c|c|c|c|c|c|c|c|}
\hline Disease & Diagnostic & Target & Energy $(\mathrm{MeV})$ & Half-life & Therapy & Target & $\begin{array}{l}\text { Energy } \\
(\mathrm{MeV})\end{array}$ & $\begin{array}{l}\text { Max } \\
\text { range }\end{array}$ & Half-life \\
\hline $\begin{array}{l}\text { Differentiated thyroid } \\
\text { cancer } \\
\text { Hyperthyroidism }\end{array}$ & $\begin{array}{l}123 \mathrm{I} \\
124 \mathrm{I}\end{array}$ & NaI symporter & $\begin{array}{l}\mathrm{EC}, 0.159(\gamma) \\
\mathrm{EC}, \beta^{+}\end{array}$ & $\begin{array}{l}13.22 \mathrm{~h} \\
4.2 \text { days }\end{array}$ & 131I & $\mathrm{NaI}$ symporter & $0.606\left(\beta^{-}\right)$ & $2 \mathrm{~mm}$ & 8 days \\
\hline Neuroendocrine tumors & $\begin{array}{l}{ }^{68} \mathrm{Ga}-D O T A T A T E \\
{ }^{68} \mathrm{Ga}-D O T A T O C \\
{ }^{68} \mathrm{Ga}-D O T A N O C\end{array}$ & $\begin{array}{l}\text { SSR } \\
\text { (mainly SSR } \\
\text { subtype 2) }\end{array}$ & $\beta^{+}$ & $68 \mathrm{~min}$ & 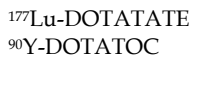 & $\begin{array}{l}\text { SSR } \\
\text { (mainly SSR } \\
\text { subtype 2) }\end{array}$ & $\begin{array}{l}0.498\left(\beta^{-}\right) \\
2.3\left(\beta^{-}\right)\end{array}$ & $\begin{array}{l}1.7 \mathrm{~mm} \\
11 \mathrm{~mm}\end{array}$ & $\begin{array}{l}6.65 \text { days } \\
2.7 \text { days }\end{array}$ \\
\hline Metastatic prostate cancer & $\begin{array}{l}{ }^{68} \mathrm{Ga}-\mathrm{PSMA} \\
{ }^{18} \mathrm{~F}-\mathrm{DCFPyL}\end{array}$ & PSMA & $\beta^{+}$ & $68 \mathrm{~min}$ & $\begin{array}{l}{ }^{177} \mathrm{Lu}-\mathrm{PSMA} \\
{ }^{125} \text { Ac-PSMA }\end{array}$ & PSMA & $\begin{array}{l}0.498\left(\beta^{-}\right) \\
5.8(\alpha)\end{array}$ & $\begin{array}{l}1.7 \mathrm{~mm} \\
<100 \mu \mathrm{m}\end{array}$ & $\begin{array}{l}6.65 \text { days } \\
10 \text { days }\end{array}$ \\
\hline & ${ }^{68} \mathrm{Ga}-\mathrm{RM} 2$ & GRPR & $\beta^{+}$ & $110 \mathrm{~min}$ & ${ }^{177} \mathrm{Lu}-\mathrm{RM} 2$ & GRPR & $0.498\left(\beta^{-}\right)$ & $1.7 \mathrm{~mm}$ & 6.65 days \\
\hline Bone metastases & $\begin{array}{l}\text { 99mTc-HDP } \\
\text { 99mTc-MDP }\end{array}$ & $\begin{array}{l}\text { New bone } \\
\text { formation }\end{array}$ & $141(\gamma)$ & $6 \mathrm{~h}$ & $\begin{array}{l}{ }^{223} \mathrm{Ra} \\
{ }_{153} \mathrm{Sm} \text {-EDTMP }\end{array}$ & $\begin{array}{l}\text { Calcimimetic } \\
\text { New bone } \\
\text { formation }\end{array}$ & $5-7.5(\alpha)$ & $<100 \mu \mathrm{m}$ & 11.4 days \\
\hline $\begin{array}{l}\text { Neuroblastoma } \\
\text { Pheochromocytoma } \\
\text { Paraganglioma }\end{array}$ & 123I-mIBG & $\begin{array}{l}\text { Norepinephrine } \\
\text { transporter }\end{array}$ & $159 \mathrm{keV}(\mathrm{\gamma})$ & $13.3 \mathrm{~h}$ & 131 I-mIBG & $\begin{array}{l}\text { Norepinephrine } \\
\text { transporter }\end{array}$ & $0.606\left(\beta^{-}\right)$ & $2 \mathrm{~mm}$ & 8 days \\
\hline
\end{tabular}

From a therapeutic point of view, treatment with 131I is given in various settings: In benign hyperthyroidism to ablate uni- or multinodular toxic goiter or whole organ ablation in Graves' disease; in DTC, as adjuvant therapy to irradiate local or distant metastases and thereby reducing the risk of recurrence, or for residual or recurrent disease, or to ablate any normal thyroid remnant after total thyroidectomy to ensure an undetectable thyroglobulin level which subsequently can be used as tumor marker in follow-up [15, 16]. The American Thyroid Association (ATA) guidelines from 2015 recommended radioiodine treatment for high-risk patients, selected cases with intermediate-risk, but not in patients with low-risk disease [15]. However, two randomized clinical trials from Europe validated the treatment of low-risk patients with a low activity of $1.1 \mathrm{GBq}{ }^{131} \mathrm{I}$ $[17,18]$ and showed that the rate of relapse was not higher in patients who received 1.1 GBq vs 3.7 GBq 131I [18]. Further large, randomized studies are underway to evaluate the usefulness of radioiodine treatment in low-risk DTC patients (ClinicalTrials.gov identifiers NCT01837745, NCT01398085). In a joint statement of the ATA, the European Association of Nuclear Medicine, the Society of Nuclear Medicine and Molecular Imaging, and the European Thyroid Association, they acknowledged the lack of substantial data pro or contra radioiodine treatment in low-risk DTC patients and concluded that the decision to treat should be made on an individual basis depending on disease risk factors, patient-related factors (concern, co-morbidities) and healthcare setting [16].

Theranostic with radioiodine is an integral part of (re-)staging, therapy, and surveillance of DTC after initial thyroidectomy. Although the prognosis of DTC is usually favorable, recurrence is seen in $5-30 \%$ of the cases [19]. Treatment of recurrent or metastatic disease is problematic, especially when these tumors have become refractory to radioiodine [20]. MEK inhibitors such as selumetinib have shown ability to induce redifferentiation of radioiodine refractory cancer cells and hence increased radioiodine uptake in a small cohort [21]. The SEL-I-METRY trial, a multicenter phase II study (European Union Clinical Trials Register identifier EudraCT 2015-002269-47), is underway to shed more light on the redifferentiation potential of selumetinib.

Medullary thyroid cancer (MTC) derives from C-cells which arise from the neural crest and is therefore considered NET. Primary and curative treatment is surgery. In case of progressive, symptomatic disease, systemic therapy with cabozantinib and vandetanib is recommended [22, 23]. However, these multikinase inhibitors bear serious adverse reactions and have not shown a significant survival benefit. As MTC are NET, peptide receptor radionuclide therapy (PRRT) with ${ }^{90} \mathrm{Y}$-DOTA TOC, which targets somatostatin receptors (SSR), has been evaluated. A phase II trial evaluating response, survival, and long-term safety of ${ }^{90} \mathrm{Y}$-DOTATOC in patients with metastatic MTC and increasing tumor marker calcitonin showed that $29 \%$ of patients demonstrated a decrease in tumor marker which was associated with a significantly higher survival [24]. Other studies exploring ${ }^{177} \mathrm{Lu}-D O T A T A T E ~[25]$ and ${ }^{177} \mathrm{Lu}$-octreotate [26] concluded that PRRT can be considered as alternative. However, PRRT has not yet become clinical routine. Lodewijk et al showed expression of prostate-specific membrane antigen (PSMA) in 90\% of the 104 included MTC patients [27]. This might warrant future TRT with ${ }^{177} \mathrm{Lu}-\mathrm{PSMA}$ which is currently used to treat prostate cancer (PC) in clinical trials. Interestingly, a recently published case report showed uptake of ${ }^{18} \mathrm{~F}-\mathrm{FDG},{ }^{68} \mathrm{Ga}$-DOTATATE and ${ }^{68} \mathrm{Ga}-\mathrm{PSMA}$ in a patient with radioiodinerefractory, poorly differentiated thyroid cancer [28]. Rottenburger et al reported the first in man administration of the cholecystokinin-2 receptor agonist ${ }^{177} \mathrm{Lu}-\mathrm{PP}-\mathrm{F} 11 \mathrm{~N}$ in patients with MTC. 
${ }^{177} \mathrm{Lu}-\mathrm{PP}-\mathrm{F} 11 \mathrm{~N}$ showed promising biodistribution with accumulation in MTC lesions [29]. Clearly there is an unmet need for treatment of metastatic MTC. Further randomized clinical trials are needed to compare different TRT with current state-of-the-art multikinase inhibitors in patients with MTC.

\section{Neuroendocrine Tumors - PRRT}

NETs are a heterogenous group of rare tumors. The majority are gastroenteropancreatic NETs (GEP-NET) (60-70\%) and bronchial NETs (30\%). Although considered rare, their incidence is rising, which might be due to more awareness and incidental findings, but also related to rapidly developing diagnostic methods [30]. The classification and nomenclature of NET is complex and not uniform as studies have mostly been focusing on organ-specific NETs. The World Health Organization proposed a 'common framework' to classify NETs: Depending on the site of origin, neuroendocrine neoplasia are divided into NETs and neuroendocrine carcinomas (NEC). NETs are further characterized by grading (low, intermediate, and high grade) based on mitotic rate and ki-67 index, which is a marker for cell proliferation [31]. The distinctive feature of well-differentiated NETs is the overexpression of SSR on their cell surface $[32,33]$. Somatostatin is in control of hormone secretion such as glucagon, insulin and growth hormone, and cell proliferation [34]. Five subtypes of human SSRs have been identified: 1, 2A, 2B, 3, 4 and 5. The majority of NETs show overexpression of subtype 2, especially $90 \%$ of GEP-NETs [35-37]. Poorly differentiated NETs and NECs have less or no expression of SSR [37]. Somatostatin analogs (SSA) were developed to target SSR and were initially administered to relieve symptomatic burden of functioning NETs. As they also showed an antiproliferative effect, their use was expanded to include non-hormone-secreting NETs [38, 39]. SSA can be radiolabeled to image SSR expression for theranostic purposes. The diagnostic counterpart for SPECT imaging is ${ }^{111} \mathrm{In}$-octreotide or ${ }^{99 \mathrm{~m} T c-H y n i c-t o c . ~}$ However, SPECT imaging has been largely replaced by PET due to better image quality and its potential for quantification [40]. Currently, there are three well established SSA available that are conjugated to DOTA and labeled with ${ }^{68} \mathrm{Ga}:{ }^{68} \mathrm{Ga}-\mathrm{DOTA}-1-\mathrm{Nal3}-$ octreotide (DOTANOC), ${ }^{68}$ Ga-DOTA-D-Phe1-Tyr3octreotide (DOTATOC) and ${ }^{68} \mathrm{Ga}-\mathrm{DOTA}-\mathrm{D}-\mathrm{Phe1}-$ Tyr3-Thr8-octreotide (DOTATATE). DOTATATE has a 10-fold higher and selected affinity to SSR2 receptor followed by DOTATOC which also binds to SSR5, whereas DOTANOC is selective towards SSR2, SSR3 and SSR5 [41]. Despite their different affinity to the various SSR, they all show high affinity to SSR2 and are equally effective in diagnostic accuracy with a pooled sensitivity of $93-96 \%$ and specificity of $85-100 \%$ [42-50] making PET imaging with ${ }^{68} \mathrm{Ga}$-labeled SSA a powerful tool. In a systematic review and meta-analysis on the impact of ${ }^{68} \mathrm{Ga}-\mathrm{SSA}$ PET on patient management including 1,561 patients, a management change due to PET/CT findings was seen in $44 \%$. Most interestingly, $77 \%$ were intermodality changes, meaning a change in type of treatment (e.g., surgery to chemotherapy). Recently, the FDA approved Copper-64 $\left({ }^{64} \mathrm{Cu}\right)$-DOTATATE for PET imaging of SSR positive NETs. ${ }^{64} \mathrm{Cu}$ has the advantage of a longer half-life (12.7 hours vs 68 minutes of ${ }^{68} \mathrm{Ga}$ ), which makes a central production with long haul distribution possible. In a phase III clinical trial evaluating ${ }^{64} \mathrm{Cu}$-DOTATATE PET/CT imaging for NET, a 100\% sensitivity and 96.8\% specificity was found with no adverse events [51]. ${ }^{68} \mathrm{Ga}-\mathrm{DOTATOC}$ has also been FDA approved based on two clinical trials [52, 53], however, it has no commercial partner yet.

The therapeutic counterpart uses the same SSA radiolabeled with beta emitters like ${ }^{177} \mathrm{Lu}$ and ${ }^{90} \mathrm{Y}$ or more recently with alpha emitters such as ${ }^{225} \mathrm{Ac}$. Treatment with PRRT has been employed for a quarter of a century now. A magnitude of clinical trials and studies evidence the efficacy of PRRT in terms of decrease in tumor size and tumor marker, symptomatic relief, overall improvement of quality of life, and increase in overall survival (OS). In general, PRRT is known to have a safe profile and possesses little side effects. However, different radioisotopes have different safety profiles. Renal failure due to radiation induced inflammation and fibrosis of the kidneys has been reported, especially when using ${ }^{90} \mathrm{Y}$, but less since the introduction of nephroprotection with amino acids. Hematological toxicity is usually mild and in the majority of cases reversible [54-58]. The NETTER-1 clinical trial was the first prospective randomized phase III trial in midgut NETs comparing treatment with high dose SSA vs a combination of normal dose SSA and PRRT with ${ }^{177} \mathrm{Lu}$-DOTATATE. At the data-cutoff date, the median progression free survival (PFS) had not been reached in the PRRT group vs 8.4 months in the SSA group, meaning a 79\% lower risk of disease progression or death in the PRRT arm. Partial response of $17 \%$ was seen in the ${ }^{177} \mathrm{Lu}$-DOTATATE arm vs $3 \%$ in the SSA group. The patients reported a significant improvement in quality of life compared with high-dose SSA. Adverse events were higher in the PRRT group, however only mild in nature including nausea and vomiting due to the concomitant infusion of nephroprotective amino acids, fatigue or abdominal pain, and diarrhea. Hematotoxicity grade 3-4 was low and included 
neutropenia, thrombocytopenia, and lymphopenia in $1 \%, 2 \%$, and $9 \%$ of patients, respectively, vs none in the SSA arm [59]. This game changing study led to the FDA and European Medicines Agency approval of ${ }^{177} \mathrm{Lu}$-DOTATATE for unresectable or metastatic, progressive, well-differentiated, SSR-positive NETs in 2018. As median PFS and OS had not been reached at the data-cutoff date, final analyses are forecasted either after 158 deaths or 5 years after randomization of the last patient and are anticipated soon.

Currently, research is shifting towards PRRT with alpha emitters. Beta emitting radionuclides have a longer range and hence penetration, which impacts adverse events. Alpha emitters not only have a short range but also deliver a high linear dose to the tumor cells, potentially increasing efficacy. Patients with GEP-NET frequently have liver-dominant disease.
Liver-directed treatment can deliver a high tumoricidal dose to the hepatic metastases while sparing surrounding healthy liver tissue. A first in human study showed promising results with liver targeted treatment with intraarterial application of Bismuth-213 (213Bi)-DOTATOC [60]. Other strategies include the use of somatostatin antagonists as antagonists seem to bind to more sites on receptors, even though they are not internalized into the cell. SSR antagonists have a favorable pharmacokinetic and better tumor visualization than agonists [61, 62]. The SSA antagonistic theranostic pair ${ }^{68} \mathrm{Ga}-$ NODAGA-JR11 and 177Lu-DOTA-JR11 (177Lu-OPS201) are currently evaluated in phase I/II multicenter studies (ClinicalTrials.gov identifiers NCT02592707, NCT02609737).

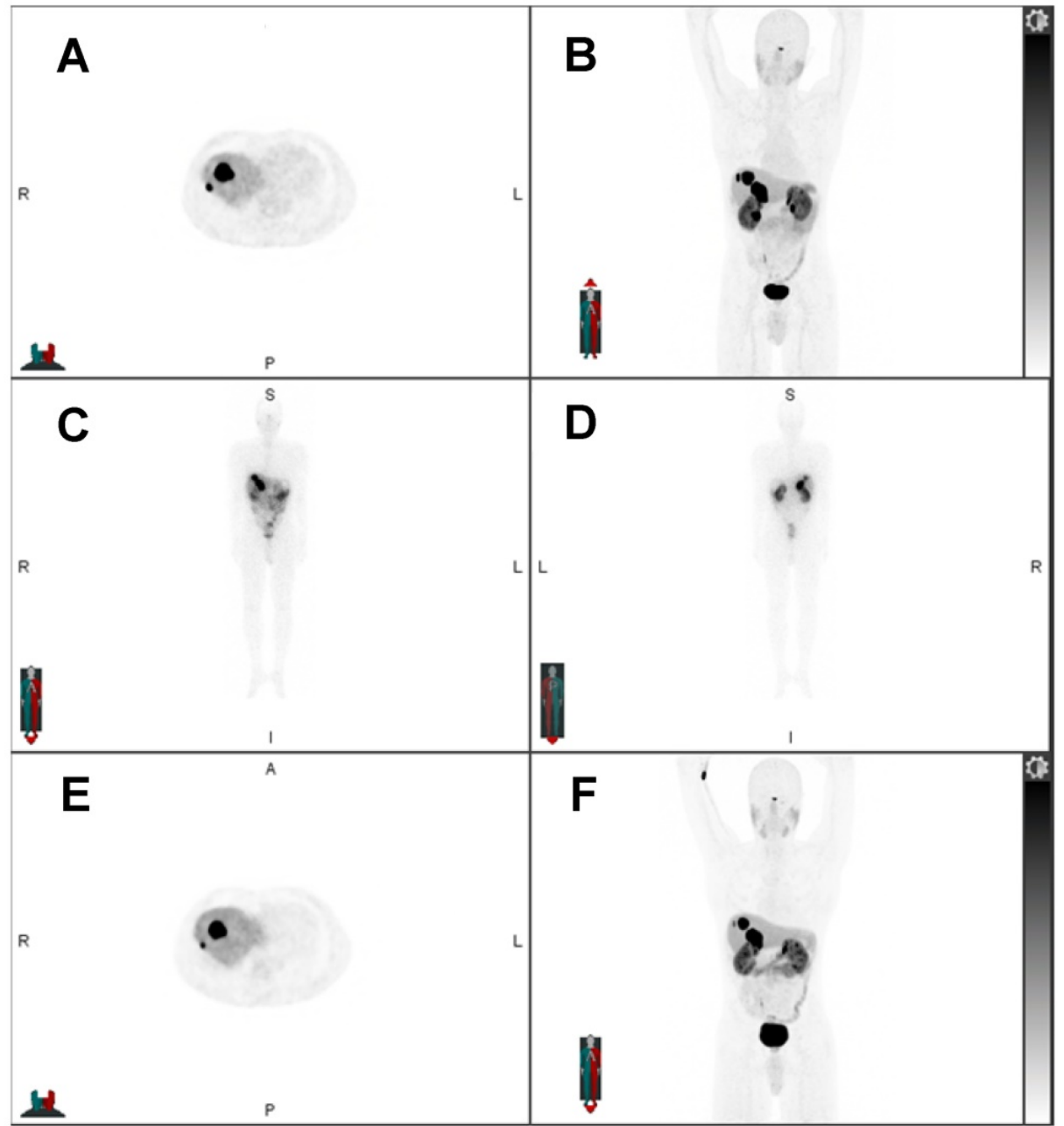

Figure 1: 55-year-old man with pancreatic NET, first diagnosed in September 2017 without hormone hypersecretory syndrome. Initial staging was pT3 N1 M1 to the liver with a ki-67 of $18.4 \%$, grade 2 . The patient underwent distal pancreatectomy, splenectomy and right hepatic lobectomy, and subsequent chemotherapy with everolimus. Restaging showed progression of liver metastases and chemotherapy with temozolomide and capecitabine was initiated. However, the liver metastases were unresponsive to chemotherapy. The patient was evaluated for PRRT and showed SSR expression. Subsequent treatment with four cycles of ${ }^{177}$ Lu-DOTATATE. Pretreatment ${ }^{68}$ Ga-DOTATATE PET showed liver-only disease: A) axial and B) maximum intensity projection (MIP) ${ }^{68 G a-D O T A T A T E ~ P E T . ~ P o s t ~}{ }^{177 L u-D O T A T A T E}$ treatment SPECT confirmed treatment targets: C) planar anterior and D) posterior view of $177 \mathrm{Lu}$-DOTATATE SPECT. Post-therapeutic whole-body SPECT/CT was obtained for treatment evaluation and dosimetric purposes. Interval ${ }^{68} \mathrm{Ga}-\mathrm{DOTATATE}$ PET after two treatment cycles showed decreased size of liver metastases with central necrosis: E) axial and F) MIP ${ }^{68 \mathrm{Ga}-\mathrm{DOTATATE} \text { PET. }}$ 


\section{Prostate Cancer - PSMA and GRPR}

PSMA is a transmembrane glycoprotein which is highly overexpressed in prostate cancer (PC) [63]. Despite the suggestive name, PSMA is also expressed on various other cancers including breast [64] and renal cell cancer [65]. High expression is correlated with advanced, high-grade, androgen-independent disease [66]. PSMA-targeted compounds are now the most widely used PET radiotracers for staging in intermediate- and high-risk disease and at biochemical recurrence, especially with low prostate specific antigen (PSA) level [67-69]. Once conjugated with the chelator DOTA, they can be labeled with positron emitters like ${ }^{18} \mathrm{~F}$ and ${ }^{68} \mathrm{Ga}$ for diagnostics and with beta $\left({ }^{90} \mathrm{Y},{ }^{177} \mathrm{Lu}\right)$ or alpha emitters $\left({ }^{213} \mathrm{Bi},{ }^{225} \mathrm{Ac}\right)$ for therapy. ${ }^{68} \mathrm{Ga}$-labeled PSMA inhibitors such as PSMA-11, PSMA-I\&T (imaging and treatment) and PSMA-617 are the most commonly used. However, ${ }^{18} \mathrm{~F}$-labeled tracers have the advantage of a slightly longer half-life (110 minutes) which allows a wider distribution along with a high yield production in a cyclotron facility. As highly anticipated, the FDA just recently approved the ${ }^{18} \mathrm{~F}$-labeled PSMA PET agent DCFPyL [70]. PSMA-617 is the most studied ligand for therapy as it showed favorable pharmacokinetics with high internalization, tumor retention and rapid renal clearance [71]. Treatment with ${ }^{177} \mathrm{Lu}-\mathrm{PSMA}$ for metastatic castration resistant PC (mCRPC) has been introduced nearly a decade ago. Results from prospective phase II clinical trials were pivotal with a decline of PSA levels of greater than $50 \%$ in $45 \%$ of patients whereas any decrease was observed in $60 \%$ of patients. Treatment response was registered in up to $82 \%$ according to Response Evaluation Criteria in Solid Tumors (RECIST) and Positron Emission Tomography Response Criteria in Solid Tumors (PERCIST) criteria. PFS and OS were improved, and patients reported pain relief and increased quality of life. Treatment side effects were mild, including fatigue, nausea, and pain. Hematological toxicity was also reported mild and reversible in $90 \%$. However, due to the high uptake in salivary glands, xerostomia was common, however, transient [72-76]. The TheraP study, a randomized phase II trial, compared treatment with ${ }^{177} \mathrm{Lu}-\mathrm{PSMA}-617$ to chemotherapy with cabazitaxel. A higher PSA response rate $(66 \%$ vs $37 \%)$ and lower adverse events (33\% vs $53 \%)$ were seen in the ${ }^{177} \mathrm{Lu}-\mathrm{PSMA}-617$ arm compared to cabazitaxel [77]. In contrast, the VISION trial compared treatment with ${ }^{177} \mathrm{Lu}-\mathrm{PSMA}-617$ and standard of care (SOC) to SOC alone, i.e., no active chemotherapy regimen in the control group, in PSMA-positive mCRPC patients who had previously received treatment with next-generation androgen receptor signaling inhibition (abiraterone, enzalutamide, etc.) and one or two prior lines of taxane chemotherapy. The first results of this international, randomized, open-label phase III study were just presented at the annual conference of the American Society of Clinical Oncology (ASCO) in the beginning of June 2021: The treatment with ${ }^{177} \mathrm{Lu}-\mathrm{PSMA}-617$ plus SOC showed a $60 \%$ reduced risk of progression (median PFS ${ }^{177} \mathrm{Lu}-\mathrm{PSMA}-617$ and SOC vs SOC: 8.7 vs 3.4 months), and a $38 \%$ reduced risk of death (median OS ${ }^{177} \mathrm{Lu}-\mathrm{PSMA}-617$ and SOC vs SOC: 15.3 vs 11.3 months). The objective response rate was significantly higher in the $177 \mathrm{Lu}-\mathrm{PSMA}-617$ plus SOC arm than in the SOC arm (29.8\% vs $1.7 \%)$, as was the disease control rate $(89.0 \%$ vs $66.7 \%)$ and time to first symptomatic skeletal event (11.5 vs 6.8 months). Despite a higher rate of high-grade (grade 3 - 5) ${ }^{177} \mathrm{Lu}-\mathrm{PSMA}-617$ related adverse events, the treatment was well tolerated. Adverse events included bone marrow suppression, xerostomia, nausea and vomiting [78]. The sponsoring company announced that they will file for regulatory approval for ${ }^{177} \mathrm{Lu}-\mathrm{PSMA}-617$ in the US and Europe.

Alpha emitting PSMA agents for treatment have been a field of active research in the last years. In a first in man study, 225Ac-PSMA-617 achieved biochemical and radiological complete remission with low hematotoxicity but severe xerostomia, which remains the dose-limiting toxicity [79]. A retrospective analysis of ${ }^{225}$ Ac-PSMA-617 TRT in 73 patients showed a decline in PSA greater than or equal to $50 \%$ in $70 \%$ of patients, which was associated with a longer OS. The median PFS was 15.2 months and OS was 18 months. Xerostomia was seen in $85 \%$ of patients but did not lead to discontinuation of treatment [80]. However, the patient population was less pre-treated than in comparable studies [81]. More prospective studies comparing alpha emitting agents to chemotherapy are needed.

Gastrin releasing peptide receptor (GRPR) has emerged as a promising novel target. It is highly expressed in PC and shows only low expression in benign prostate tissue [82]. Initially, GRPR agonists were synthesized but due to their internalization into the cell, caused side effects. Inspired by research on SSR antagonists, research shifted towards GRPR antagonists. The most studied and promising compound is ${ }^{68} \mathrm{Ga}-\mathrm{RM} 2$ which has been evaluated for initial diagnosis $[83,84]$ and biochemical recurrent disease $[85,86]$ and showed promising results with high tumor uptake and favorable biodistribution. However, one caveat is that GRPR imaging might be limited in patients with hormonal treatment as this may affect GRPR expression in the tumors [87]. More prospective trials with larger cohorts using GRPR 
antagonists are needed, especially in comparison to the currently most widely used ${ }^{68} \mathrm{Ga}-\mathrm{PSMA}-11$, to better understand their relationship and potential predictive value of tumor biology and aggressiveness in different types and stages of PC.

Several theranostic pairs were investigated preclinically, however the first compound explored in human is ${ }^{177} \mathrm{Lu}-\mathrm{RM} 2$ [88]. Four patients with mCRPC without any further treatment options were treated with ${ }^{177} \mathrm{Lu}-\mathrm{RM} 2$ after prior confirmation of GRPR expression through ${ }^{68} \mathrm{Ga}-\mathrm{RM} 2 \mathrm{PET} / \mathrm{CT}$. The highest absorbed doses were seen in bone lesions, followed by lymph node and soft tissue metastases and were all therapeutically relevant. The highest physiologic uptake was measured in the pancreas, which became the dose limiting organ [88]. A phase I/IIa open-label, multicenter trial is currently underway evaluating biodistribution, dosimetry and safety, tolerability, and antineoplastic activity of the GRPR antagonist ${ }^{177} \mathrm{Lu}-\mathrm{NeoB}$ in patients with GRPR expressing, metastatic solid tumors (ClinicalTrials.gov identifier NCT03872778).

\section{Bone Seeking Pseudotheranostic Pairs}

Many cancers metastasize to the skeleton causing pain, pathologic fractures, and spinal cord compression thus driving morbidity and mortality. Osteoblastic metastases are characterized by increased bone metabolism which can be targeted by bone seeking radiopharmaceuticals such as 99mTc-biphosphonates for SPECT and sodium fluoride-18 $\left(\mathrm{NaF}^{18}\right)$ for PET imaging, and subsequent treatment labeled to an alpha or beta emitter. Bone seeking radiopharmaceuticals accumulate in the bone depending on the degree of osseous metabolism, meaning the higher the bone turnover, the higher the accumulation of the radiopharmaceutical, hence higher affinity to osteoblastic metastases than healthy bone [89]. Bone palliation has been first treated with ${ }^{32} \mathrm{P}$ and subsequently other beta emitters such as Strontium-89 ( $\left.{ }^{89} \mathrm{Sr}\right)$, Rhenium-186-hydroxyethylidene diphosphonate (186Re-HEDP), ${ }^{153} \mathrm{Sm}$-ethylenediamine tetramethylene phosphonate $\left({ }^{153} \mathrm{Sm}-\mathrm{EDTMP}\right),{ }^{177} \mathrm{Lu}-$ EDTMP, and the alpha emitter ${ }^{223} \mathrm{Ra}$. Bone seeking agents can be grouped into calcium analogs like ${ }^{89} \mathrm{Sr}$ and ${ }^{223} \mathrm{Ra}$, and radionuclides labeled to a phosphate like ${ }^{186} \mathrm{Re}-\mathrm{HEDP}$ and ${ }^{153} \mathrm{Sm}$-EDTMP. For radiolabeled phosphates and ${ }^{89} \mathrm{Sr}$, bone palliation has been shown to occur 2 - 10 days after treatment with overall pain relief response rate of $59-86 \%$. However, survival is not significantly impacted [90-97].

${ }^{223} \mathrm{Ra}$-dichloride is the currently most widely and commonly used bone targeted treatment. It has been FDA approved in 2013 for symptomatic bone metastases in mCRPC without known visceral metastases. ${ }^{223} \mathrm{Ra}$ is a calcium analog, which forms complexes with the bone mineral hydroxyapatite in areas of high bone metabolism. It therefore does not target the tumor cell itself but rather accumulate in between them. The short range of the alpha emitter allows high LET to the tumor stroma, causing DNA double-strand breaks, but minimizes damage to the surrounding normal tissue, especially the bone marrow [98]. The landmark study which led to approval was the ALSYMPCA trial, a randomized double blinded multicenter phase III clinical trial. Patients, before or after chemotherapy with docetaxel, were stratified in a treatment group which received six cycles of ${ }^{223} \mathrm{Ra}$ with an interval of four weeks, and a placebo group receiving best supportive care. The key results were a significant delay in time to first symptomatic skeletal event in the ${ }^{223} \mathrm{Ra}$ group vs placebo group (15.6 vs 9.8 months) and better OS (14.9 vs 11.3 months). Adverse events were seen slightly more frequently in the placebo than in the ${ }^{223} \mathrm{Ra}$ group $(96 \%$ vs $93 \%)$. ${ }^{223} \mathrm{Ra}$ related side effects included mainly hematotoxicity, nausea, and other gastrointestinal reactions. Quality of life has been significantly improved in the treatment group [99]. PSA showed to be unreliable for response assessment. First treatment effects were reduced bone pain (typically after two weeks) or decreased alkaline phosphatase. Furthermore, the ALSYMPCA trial showed that ${ }^{223} \mathrm{Ra}$ was safe and effective when used before or after chemotherapy with docetaxel. However, concurrent ${ }^{223} \mathrm{Ra}$ therapy and chemotherapy is not recommended. Adding ${ }^{223} \mathrm{Ra}$ therapy to abiraterone or enzalutamide has been reported safe, however the combination treatment did not improve bone palliation, on the contrary, was associated with increased incidence of pathologic fractures and mortality [100]. A small clinical trial showed that patients who had previously been treated with ${ }^{223} \mathrm{Ra}$ and progressed afterwards can be safely re-treated without serious drug-related adverse events in a two year follow up after re-treatment [101].

Although ${ }^{223} \mathrm{Ra}$ was only approved for $\mathrm{PC},{ }^{223} \mathrm{Ra}$ could target osteoblastic metastases of any malignant origin. A recently published phase II study showed high disease control rate of $49 \%$ and tumor response rate of $54 \%$ of ${ }^{223} \mathrm{Ra}$ combined with hormonal therapy in hormone receptor-positive, bone-dominant metastatic breast cancer [102]. Osteosarcoma cells are also known to have a high avidity for bone seeking agents, not only at the primary site but also in soft tissue metastases, therefore making ${ }^{223} \mathrm{Ra}$ an ideal systemic therapy for patients with metastatic osteosarcoma. A single phase I dose escalation study has been published hitherto showing feasibility and safety of up to six cycles ${ }^{223} \mathrm{Ra}$ with minimal 
hematologic toxicity in a small cohort of 18 patients with high-risk osteosarcoma [103]. Further studies are expected.

\section{Neuroblastoma, Pheochromocytoma, Paraganglioma - mIBG}

Neuroblastoma is the most frequent extracranial solid tumor in infancy which derives from primitive neural crest cells from the sympathetic nervous system. These tumors are heterogenous in nature, varying in location, and clinical behavior ranging from spontaneous regression to aggressive, metastatic disease [104, 105]. Pheochromocytoma and paraganglioma (PPGL) are also rare tumors arising from the neural crest. Pheochromocytomas originate from the adrenal medulla and paragangliomas from extra-adrenal, the sympathetic or parasympathetic ganglia. As these tumors are very heterogenous, their management is challenging, especially in the advanced, metastatic setting [106-108]. The distinct feature of tumors deriving from the neural crest is the overexpression of norepinephrine transporter on their cell membrane. This is found in $90 \%$ of neuroblastomas [109] and 50-60\% of PPGL, whereas expression might be low in head and neck paragangliomas [110]. High expression of norepinephrine transporter is also found in other NETs like GEP-NET, MTC, Merkel cell carcinoma, and ganglioneuroma. Meta-iodobenzylguanidine (mIBG) is a norepinephrine analog which is taken up by norepinephrine transporters and subsequently stored in neurosecretory granules via vesicular monoamine transporters 1 and 2, thus irradiating the cancer cell when radiolabeled to ${ }^{131}$ I [107]. ${ }^{131}$ I-mIBG has been approved by the FDA in late 2018 for the treatment of mIBG positive, unresectable, locally advanced, or metastatic pheochromocytoma or paraganglioma based on the results of an open-label, single-arm, multicenter clinical trial involving 68 patients. Treatment response was achieved in $22 \%$ of patients receiving a single dose and increased to $32 \%$ in patients who received two doses. Ninety-two percent of patients who received at least one dose, showed partial response or stable disease. The median OS was 36.7 months. Clinical benefit was reflected in a $50 \%$ or greater reduction of all antihypertensive medication for at least six months in $25 \%$ of patients. Patients

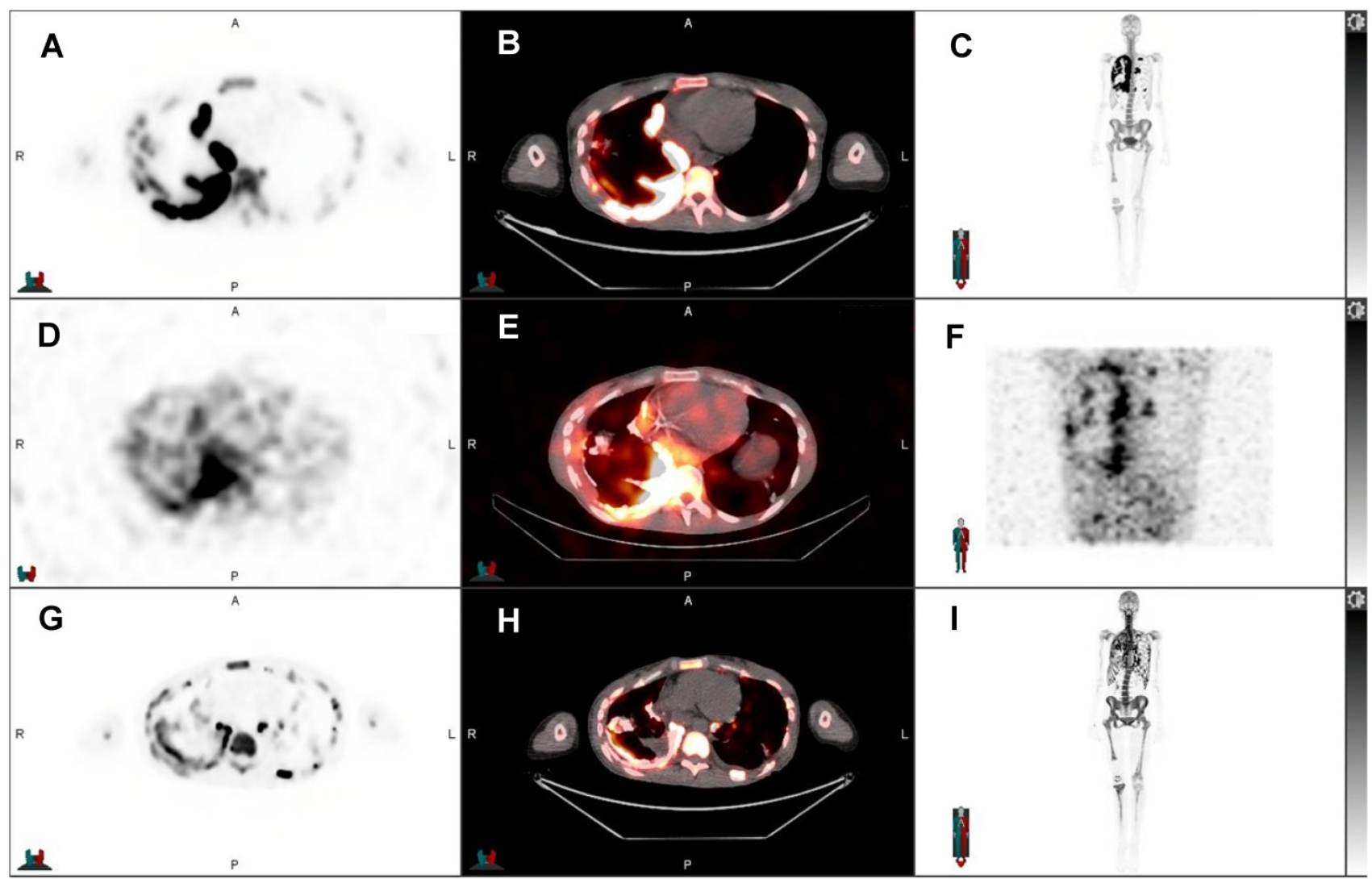

Figure 2: 32-year-old woman with progressive metastatic osteosarcoma to the pleura, first diagnosed in February 2019. She underwent resection of the primary tumor in the right knee and multiple lines of chemotherapy. As her disease burden markedly increased with extensive right pleural metastases, few left pleural metastases, and right internal mammary, mediastinal, and hilar nodal metastases, she was referred for ${ }^{223} \mathrm{Ra}$ treatment under compassionate care. Pretreatment $\mathrm{Na}-18 \mathrm{~F}$ PET/CT showed uptake in the pleura: A) Axial Na-18F PET, B) axial fused Na-18F PET/CT, C) MIP Na-18F PET. Post ${ }^{223}$ Ra therapy SPECT/CT evidenced uptake of $223 \mathrm{Ra}$ in the calcified osteosarcoma lesions in the pleura:

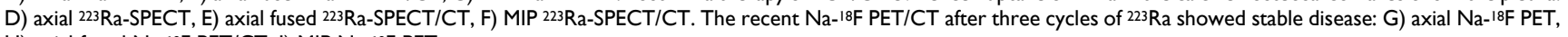
$\mathrm{H})$ axial fused $\mathrm{Na}-18 \mathrm{~F} \mathrm{PET} / \mathrm{CT}, \mathrm{I}) \mathrm{MIP} \mathrm{Na}-{ }^{18} \mathrm{~F} \mathrm{PET}$. 
without hypertension were not included in this study, however, this might not have an impact on overall oncologic course of disease. The most common side effect was of hematologic nature in $90 \%$ of patients, whereas $72 \%$ were severe (grade 3-4). Despite the high percentage of severe adverse events, they were transient and resolved without intervention in all but $25 \%$ who needed supportive care such as red blood cell and platelet transfusion, granulocyte colony-stimulating factors or erythropoietin for a limited time. In $16 \%$ of patients, ${ }^{131}$ I-miBG treatment had to be discontinued due to persistent severe myelosuppression or other non-hematologic adverse reactions such as nausea. Myelodysplastic syndrome was seen in $4 \%$ and acute leukemias in 3\% [111]. Of note is that patients in this study were not prospectively stratified by genetic mutations. Especially succinate dehydrogenase complex iron sulfur subunit B (SDHB) mutations are associated with an unfavorable prognosis, and false negative ${ }^{123}$ I-mIBG scans have been reported [112]. Patient preparation for ${ }^{131} \mathrm{I}-\mathrm{mIBG}$ diagnostic and treatment includes discontinuation of medication that interfere with norepinephrine transporters for at least five half-lives before and seven days after treatment (i.e., blood pressure medication such as combined alpha/beta blocker labetalol and calcium channel blockers, antidepressants, tramadol and pseudoephedrine) to avoid any false negative scans or transporter saturation a priori. As mIBG is radiolabeled with ${ }^{131} \mathrm{I}$, thyroid blockade should be given at least 24 hours prior to treatment and ten days afterward.

For neuroblastoma, therapy with ${ }^{131} \mathrm{I}-\mathrm{mIBG}$ showed promising results with a $30 \%-40 \%$ response rate, especially in high-risk neuroblastoma with refractory, relapsed or resistant conditions [113, 114]. Hematological side effects are commonly seen, often amplified by combined chemotherapy.

As PPGL are also NETs, they express SSR on their cell surface which makes theranostic with ${ }^{68} \mathrm{Ga}$-DOTATATE and ${ }^{177} \mathrm{Lu}$-DOTATATE possible. Especially in patients with metastatic, extra-adrenal primaries or familial PPGL, the sensitivity of mIBG may drop to $53-61 \%$. SDHB mutation is the most common germline mutation seen in PPGL. It is characterized by a high malignant transformation $(30 \%)$, shorter survival (5-year survival rate $36 \%$ vs $67 \%$ in patients without SDHB mutation) and $20 \%$ do not produce norepinephrine $[115,116]$. These patients might benefit from PRRT. In hereditary forms and germline mutations, the various radiopharmaceuticals for molecular imaging allow for stratification and selection of the right treatment for the patient.

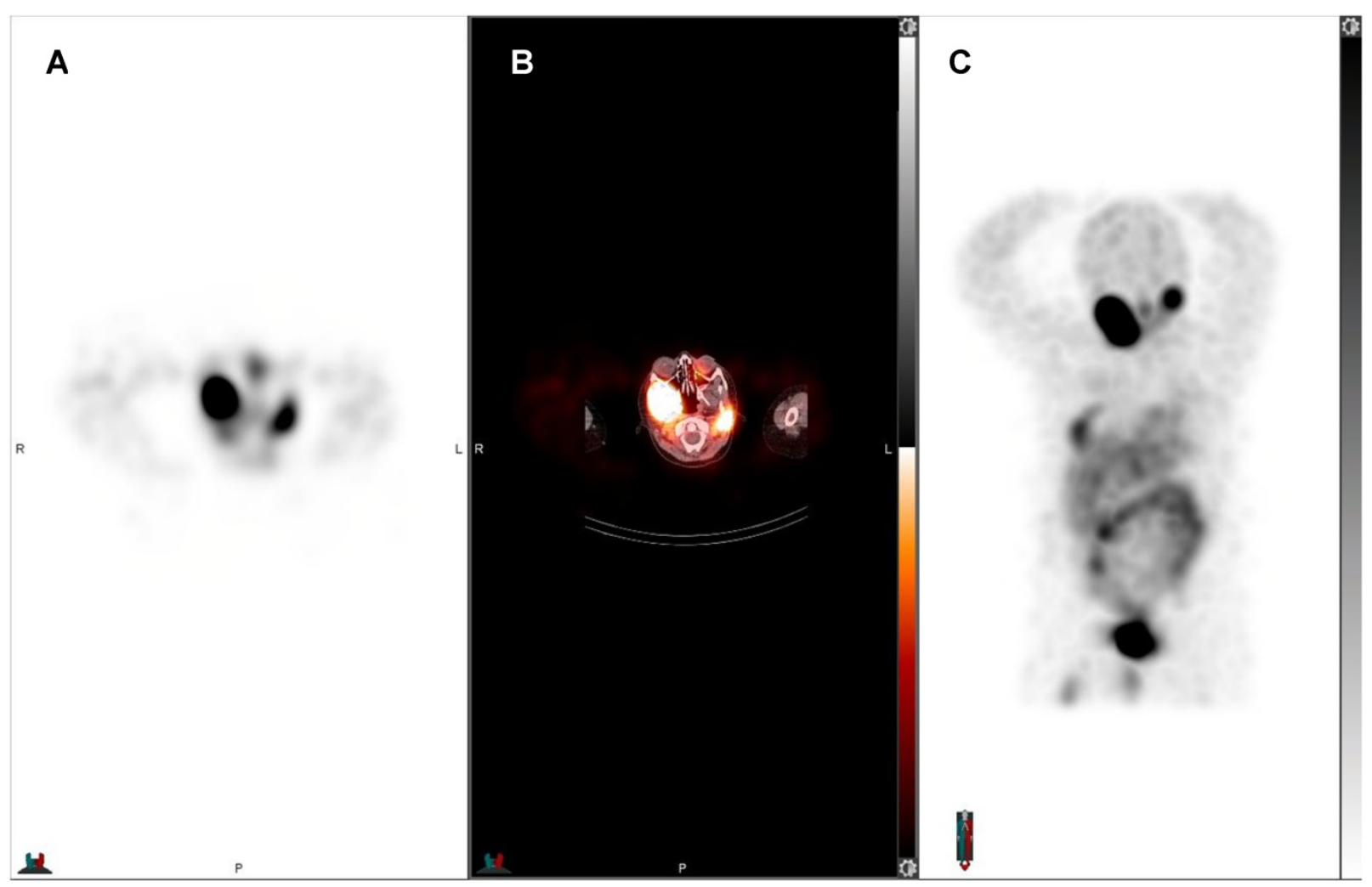

Figure 3: Post-therapeutic $131 \mathrm{l}$-mIBG SPECT/CT of an 8-year-old boy with progressive refractory metastatic stage IV ganglioneuroblastoma. After initial $131 \mathrm{I}$-mIBG SPECT/CT showed ${ }^{131}$ I-mIBG uptake in the sites of progressive disease in the hemimandible, femur, proximal tibia, and $7^{\text {th }}$ rib, all right sighted, and mastoid left, the patient received ${ }^{131}$ I-mIBG therapy. A) Axial ${ }^{131} \mid$-mIBG SPECT, B) axial fused I3II-mIBG SPECT/CT, C) MIP I3II-mIBG SPECT. The post-therapeutic scan served as treatment verification and was used for dosimetry. ${ }^{131} \mid-\mathrm{mIBG}$ SPECT/CT showed uptake of $|31|$-mIBG in the aforementioned sites of disease. 


\section{Future Developments in Theranostics}

Active preclinical research has resulted in the development of new molecular targets with high potential in translating into the clinic and application through theranostics. Here, we present just a few of the many novel targets evolved.

\section{Fibroblast Activation Protein Inhibitors - FAPI-04}

A malignant tumor contains not only cancer cells but also non-malignant cells such as inflammatory and vascular cells, and fibroblasts that form the tumor microenvironment, the so-called tumor stroma. Cancer-associated fibroblasts make $90 \%$ of the tumor mass and highly express the membrane bound glycoprotein fibroblast activation protein (FAP) in epithelial carcinomas, especially in colorectal, breast, pancreatic and PC [117]. FAP is involved in tumor proliferation and escape from immunosurveillance [118, 119]. Various small molecule FAP inhibitors (FAPI) have been developed for imaging and treatment with promising results. ${ }^{68} \mathrm{Ga}$-FAPI-02 and ${ }^{68} \mathrm{Ga}-\mathrm{FAPI}-04$ showed high uptake in several cancers with the highest uptake in sarcoma, esophageal, breast, lung and cholangiocellular carcinoma [120]. Preclinical studies on human pancreatic cancer cells with ${ }^{225} \mathrm{Ac}-\mathrm{FAPI}-04$ showed significant tumor growth delay [121]. In a first in man study, ${ }^{90}$ Y-FAPI-04 was administered to one patient with metastasized breast cancer and reduced pain medication significantly. Despite the high uptake in the tumors, a fast clearance was observed [122]. Improved ligands with a longer tumor retention time are needed to improve tracer pharmacokinetics. Clinical data on treatment with FAPI are yet scarce.

\section{Neurotensin}

Neurotensin is a neuropeptide exhibited by the gastrointestinal and central nervous system as well as the myocardium. Neurotensin receptor 1 has been found to be overexpressed in various cancers such as colorectal, small cell and non-small cell bronchial, breast and pancreatic cancer. A first in man study showed the feasibility of treatment with ${ }^{177} \mathrm{Lu}-3 \mathrm{BP}-227$ in six patients with pancreatic adenocarcinoma. The therapy was well tolerated with reversible grade 2 anemia as adverse event. One patient achieved partial response and significant improvement of symptoms while the other survived 11 months after treatment with ${ }^{177} \mathrm{Lu}-3 \mathrm{BP}-227$ [123]. Currently, a multicenter phase I/II clinical trial is underway to evaluate the safety, tolerability, biodistribution and antitumor activity of ${ }^{177} \mathrm{Lu}-3 \mathrm{BP}-227$ in solid tumors expressing neurotensin receptor 1 (ClinicalTrials.gov identifier NCT03525392).

\section{Immuno-agents}

The CXC-chemokine receptor type 4 (CXCR-4) is highly overexpressed in various human cancers like leukemia, lymphoma, and multiple myeloma [124]. Receptor imaging with ${ }^{68} \mathrm{Ga}$-labeled pentixafor has shown promising results for imaging of multiple myeloma and lymphoma. A first in human study explored ${ }^{177} \mathrm{Lu}$ - and ${ }^{90} \mathrm{Y}$-labeled pentixather for the treatment of relapsed multiple myeloma and showed partial and complete response to CXCR4-directed treatment [125].

The anti-CD20 monoclonal antibody rituximab is a standard treatment for B-cell non-Hodgkin lymphoma. In the setting of relapsed or refractory disease, ${ }^{131}$ I-tositumomab and ${ }^{90}$ Y-ibritumomab tiuxetan have demonstrated efficacy [126, 127]. However, anti-CD20 resistant disease calls for the necessity of other targets. The CD37 targeting agent ${ }^{177} \mathrm{Lu}$-lilotomab satetraxan has been explored in a phase I/IIa study with an overall response rate of $70 \%$ whereas 32\% showed complete response [128]. Adverse events included transient grade 3 and 4 neutropenia and thrombocytopenia. These very promising results warrant future clinical trials.

Future objectives of theranostics not only include the development of new molecular targets, but also improvement of currently available treatments. The implementation of TRT earlier in the course of disease might improve quality of life as reported side effects from chemotherapies and other targeted systemic treatments are higher $(52,53)$. Dosimetry estimates cumulated radiation dose and in a personalized medicine fashion will allow for individualized dosing and number of treatment cycles as opposed to current fixed regimen of dose and treatment cycles [129]. Currently, TRT mostly aim at stabilizing disease and improving quality of life in the palliative setting. However, a combination of treatments, especially in the early stage of disease might have potential of achieving complete remission. This is currently explored in small-cell lung cancer treated with 177Lu-DOTATATE combined with nivolumab (ClinicalTrials.gov identifier NCT03325816) or in mCRPC combining treatment with ${ }^{177} \mathrm{Lu}-\mathrm{PSMA}-617$ with pembrolizumab (ClinicalTrials.gov identifier NCT03805594). Other combinations include TRT with chemotherapy and radiation therapy (65).

\section{Conclusion}

In this era of precision medicine in oncology, theranostic is the ultimate example of targeted, personalized diagnostic and treatment as we treat what we see. Each tumor's molecular profile is unique and so should the therapeutic approach be. Theranostic allows for imaging these specific tumor 
markers and patient selection and stratification so that the most beneficial treatment can be chosen. Active research in the field of theranostic will evolve more novel targets and improve radiopharmacokinetics. In the future, dosimetry will pave the way to an even more personalized treatment approach by moving from empiric standardized doses to individualized treatment doses and cycles. Molecular targeted radioligand therapy will become a major part of daily clinical nuclear medicine.

\section{Abbreviations}

${ }^{225}$ Ac: Actinium-225

ASCO: American Society of Clinical Oncology

DCFPyL:

2-(3-\{1-carboxy-5-[(6-18F-fluoro-pyridine-3-carbonyl)amino]-pentyl\}-ureido)-pentanedioic acid

DNA: Deoxyribonucleic acid

DTC: Differentiated thyroid carcinoma

DOTANOC: DOTA,1-Nal(3)-octreotide

DOTATATE: DOTA,Tyr(3)-octreotate

DOTATOC: DOTA, D-Phe1, Tyr (3)-octreotide

FAP: Fibroblast Activation Protein

FAPI: Fibroblast Activation Protein Imaging

FDA: Food and Drug Administration

${ }^{68} \mathrm{Ga}$ : Gallium-68

GEP-NET: Gastroenteropancreatic neuroendocrine tumor

GRPR: Gastrin releasing peptide receptor

123/124/131 I: Iodine-123/124/131

111In: Indium-111

LET: Linear energy transfer

${ }^{177}$ Lu: Lutetium-177

mCRPC: Metastatic castration resistant prostate cancer

miBG: Meta-iodobenzylguanidine

MTC: Medullary thyroid cancer

NaF18: Sodium fluoride-18

NET: Neuroendocrine tumor

NIS: Sodium-iodide symporter

OS: Overall survival

32P: ${ }^{32}$ Phosphorus

PC: Prostate cancer

PFS: Progression free survival

PTC: Papillary thyroid cancer

PET/CT: Positron emission tomography/computed tomography

PET/MRI: Positron emission tomography/magnetic resonance imaging

PC: Prostate cancer

PERCIST: Positron Emission Tomography Response Criteria in Solid Tumors

PPGL: Pheochromocytoma and paraganglioma

PSA: Prostate specific antigen

PSMA: Prostate specific membrane antigen
PRRT: Peptide receptor radionuclide therapy

PSMA: Prostate-specific membrane antigen

${ }^{223}$ Ra: Radium-223

186Re-HEDP: Rhenium-186 hydroxyethylidene diphosphonate

RECIST: Response Evaluation Criteria in Solid Tumors

153Sm-EDTMP: ${ }^{153}$ Samarium ethylenediamine

tetramethylene phosphonate

SOC: Standard of care

SPECT/CT: Single photon emission computed tomography/computed tomography

SSA: Somatostatin analogs

SSR: Somatostatin receptor

99mTc: Technetium-99m

TRT: Targeted radionuclide therapy

${ }^{90}$ Y: Yttrium-90

\section{Competing Interests}

The authors have declared that no competing interest exists.

\section{References}

1. Frangos S, Buscombe JR. Why should we be concerned about a "g"? Eur J Nucl Med Mol Imaging. 2019; 46: 519.

2. Bentzen SM. Theragnostic imaging for radiation oncology: dose-painting by numbers. Lancet Oncol. 2005; 6: 112-7.

3. Xie J, Lee S, Chen X. Nanoparticle-based theranostic agents. Adv Drug Deliv Rev. 2010; 62: 1064-79.

4. Lee DY, Li KC. Molecular theranostics: a primer for the imaging professional. AJR Am J Roentgenol. 2011; 197: 318-24.

5. Erf LA, Lawrence JH. Clinical Studies with the Aid of Radioactive Phosphorus. I. The Absorption and Distribution of Radio-Phosphorus in the Blood and Its Excretion by Normal Individuals and Patients with Leukemia. J Clin Invest. 1941; 20: 567-75.

6. Hertz S, Roberts A, Salter WT. Radioactive Iodine as an Indicator in Thyroid Physiology. Iv. The Metabolism of Iodine in Graves' Disease. J Clin Invest. 1942; 21: 25-9

7. Seidlin SM, Marinelli LD, Oshry E. Radioactive iodine therapy; effect on functioning metastases of adenocarcinoma of the thyroid. J Am Med Assoc. 1946; 132: 838-47.

8. $\mathrm{Ku} \mathrm{A}$, Facca VJ, Cai Z, Reilly RM. Auger electrons for cancer therapy - a review. EJNMMI Radiopharm Chem. 2019; 4: 27

9. Vaccarella S, Franceschi S, Bray F, Wild CP, Plummer M, Dal Maso L. Worldwide Thyroid-Cancer Epidemic? The Increasing Impact of Overdiagnosis. N Engl J Med. 2016; 375: 614-7.

10. Siegel RL, Miller KD, Fuchs HE, Jemal A. Cancer Statistics, 2021. CA Cancer J Clin. 2021; 71: 7-33.

11. Fagin JA, Wells SA, Jr. Biologic and Clinical Perspectives on Thyroid Cancer. N Engl J Med. 2016; 375: 1054-67.

12. Dohan O, De la Vieja A, Paroder V, Riedel C, Artani M, Reed M, et al. The sodium/iodide Symporter (NIS): characterization, regulation, and medical significance. Endocr Rev. 2003; 24: 48-77.

13. Scott DA, Wang R, Kreman TM, Sheffield VC, Karniski LP. The Pendred syndrome gene encodes a chloride-iodide transport protein. Nat Genet. 1999; 21: $440-3$.

14. Bizhanova A, Kopp P. Minireview: The sodium-iodide symporter NIS and pendrin in iodide homeostasis of the thyroid. Endocrinology. 2009; 150: 1084-90.

15. Haugen BR, Alexander EK, Bible KC, Doherty GM, Mandel SJ, Nikiforov YE, et al. 2015 American Thyroid Association Management Guidelines for Adult Patients with Thyroid Nodules and Differentiated Thyroid Cancer: The American Thyroid Association Guidelines Task Force on Thyroid Nodules and Differentiated Thyroid Cancer. Thyroid. 2016; 26: 1-133.

16. Tuttle RM, Ahuja S, Avram AM, Bernet VJ, Bourguet P, Daniels GH, et al. Controversies, Consensus, and Collaboration in the Use of (131)I Therapy in Differentiated Thyroid Cancer: A Joint Statement from the American Thyroid Association, the European Association of Nuclear Medicine, the Society of Nuclear Medicine and Molecular Imaging, and the European Thyroid Association. Thyroid. 2019; 29: 461-70.

17. Schlumberger M, Leboulleux S, Catargi B, Deandreis D, Zerdoud S, Bardet S, et al. Outcome after ablation in patients with low-risk thyroid cancer 
(ESTIMABL1): 5-year follow-up results of a randomised, phase 3, equivalence trial. Lancet Diabetes Endocrinol. 2018; 6: 618-26.

18. Dehbi HM, Mallick U, Wadsley J, Newbold K, Harmer C, Hackshaw A. Recurrence after low-dose radioiodine ablation and recombinant human thyroid-stimulating hormone for differentiated thyroid cancer (HiLo): long-term results of an open-label, non-inferiority randomised controlled trial. Lancet Diabetes Endocrinol. 2019; 7: 44-51.

19. Mazzaferri EL, Kloos RT. Clinical review 128: Current approaches to primary therapy for papillary and follicular thyroid cancer. J Clin Endocrinol Metab. 2001; 86: 1447-63.

20. Pfister DG, Fagin JA. Refractory thyroid cancer: a paradigm shift in treatment is not far off. J Clin Oncol. 2008; 26: 4701-4.

21. Ho AL, Grewal RK, Leboeuf R, Sherman EJ, Pfister DG, Deandreis D, et al. Selumetinib-enhanced radioiodine uptake in advanced thyroid cancer. N Engl J Med. 2013; 368: 623-32.

22. Elisei R, Schlumberger MJ, Muller SP, Schoffski P, Brose MS, Shah MH, et al. Cabozantinib in progressive medullary thyroid cancer. J Clin Oncol. 2013; 31: 3639-46.

23. Wells SA, Jr., Robinson BG, Gagel RF, Dralle H, Fagin JA, Santoro M, et al. Vandetanib in patients with locally advanced or metastatic medullary thyroid cancer: a randomized, double-blind phase III trial. J Clin Oncol. 2012; 30: 134-41.

24. Iten F, Muller B, Schindler C, Rasch H, Rochlitz C, Oertli D, et al. [(90)Yttrium-DOTA]-TOC response is associated with survival benefit in iodine-refractory thyroid cancer: long-term results of a phase 2 clinical trial. Cancer. 2009; 115: 2052-62.

25. Vaisman F, Rosado de Castro PH, Lopes FP, Kendler DB, Pessoa CH, Bulzico $\mathrm{DA}$, et al. Is there a role for peptide receptor radionuclide therapy in medullary thyroid cancer? Clin Nucl Med. 2015; 40: 123-7.

26. Beukhof $\mathrm{CM}$, Brabander $\mathrm{T}$, van Nederveen $\mathrm{FH}$, van Velthuysen MF, de Rijke YB, Hofland LJ, et al. Peptide receptor radionuclide therapy in patients with medullary thyroid carcinoma: predictors and pitfalls. BMC Cancer. 2019; 19: 325.

27. Lodewijk L, Willems SM, Dreijerink KMA, de Keizer B, van Diest PJ, Schepers $\mathrm{A}$, et al. The theranostic target prostate-specific membrane antigen is expressed in medullary thyroid cancer. Hum Pathol. 2018; 81: 245-54.

28. Civan C, Isik EG, Simsek DH. Metastatic Poorly Differentiated Thyroid Cancer With Heterogeneous Distribution of 18F-FDG, 68Ga-DOTATATE, and 68Ga-PSMA on PET/CT. Clin Nucl Med. 2021; 46: e212-e3.

29. Rottenburger C, Nicolas GP, McDougall L, Kaul F, Cachovan M, Vija AH, et al. Cholecystokinin 2 Receptor Agonist (177)Lu-PP-F11N for Radionuclide Therapy of Medullary Thyroid Carcinoma: Results of the Lumed Phase 0a Study. J Nucl Med. 2020; 61: 520-6.

30. Dasari A, Shen C, Halperin D, Zhao B, Zhou S, Xu Y, et al. Trends in the Incidence, Prevalence, and Survival Outcomes in Patients With Neuroendocrine Tumors in the United States. JAMA Oncol. 2017; 3: 1335-42.

31. Rindi G, Klimstra DS, Abedi-Ardekani B, Asa SL, Bosman FT, Brambilla E, et al. A common classification framework for neuroendocrine neoplasms: an International Agency for Research on Cancer (IARC) and World Health Organization (WHO) expert consensus proposal. Mod Pathol. 2018; 31: 1770-86.

32. Reubi JC, Waser B. Concomitant expression of several peptide receptors in neuroendocrine tumours: molecular basis for in vivo multireceptor tumour targeting. Eur J Nucl Med Mol Imaging. 2003; 30: 781-93.

33. Papotti $\mathrm{M}$, Bongiovanni $\mathrm{M}$, Volante $\mathrm{M}$, Allia $\mathrm{E}$, Landolfi $\mathrm{S}$, Helboe $\mathrm{L}$, et al. Expression of somatostatin receptor types 1-5 in 81 cases of gastrointestinal and pancreatic endocrine tumors. A correlative immunohistochemical and reverse-transcriptase polymerase chain reaction analysis. Virchows Arch. 2002; 440: 461-75.

34. Reubi JC, Waser B, Cescato R, Gloor B, Stettler C, Christ E. Internalized somatostatin receptor subtype 2 in neuroendocrine tumors of octreotide-treated patients. J Clin Endocrinol Metab. 2010; 95: 2343-50.

35. Modlin IM, Oberg K, Chung DC, Jensen RT, de Herder WW, Thakker RV, et al. Gastroenteropancreatic neuroendocrine tumours. Lancet Oncol. 2008; 9: 61-72.

36. Reubi JC, Waser B, Liu Q, Laissue JA, Schonbrunn A. Subcellular distribution of somatostatin sst2A receptors in human tumors of the nervous and neuroendocrine systems: membranous versus intracellular location. J Clin Endocrinol Metab. 2000; 85: 3882-91.

37. Reubi JC. Peptide receptor expression in GEP-NET. Virchows Arch. 2007; 451 Suppl 1: S47-50

38. Rinke A, Wittenberg M, Schade-Brittinger C, Aminossadati B, Ronicke E, Gress TM, et al. Placebo-Controlled, Double-Blind, Prospective, Randomized Study on the Effect of Octreotide LAR in the Control of Tumor Growth in Patients with Metastatic Neuroendocrine Midgut Tumors (PROMID): Results of Long-Term Survival. Neuroendocrinology. 2017; 104: 26-32.

39. Oberg K, Knigge U, Kwekkeboom D, Perren A, Group EGW. Neuroendocrine gastro-entero-pancreatic tumors: ESMO Clinical Practice Guidelines for diagnosis, treatment and follow-up. Ann Oncol. 2012; 23 Suppl 7: vii124-30.

40. Hofmann M, Maecke $\mathrm{H}$, Borner R, Weckesser E, Schoffski P, Oei L, et al. Biokinetics and imaging with the somatostatin receptor PET radioligand (68)Ga-DOTATOC: preliminary data. Eur J Nucl Med. 2001; 28: 1751-7.

41. Oksuz MO, Winter L, Pfannenberg C, Reischl G, Mussig K, Bares R, et al. Peptide receptor radionuclide therapy of neuroendocrine tumors with (90)Y-DOTATOC: is treatment response predictable by pre-therapeutic uptake of (68)Ga-DOTATOC? Diagn Interv Imaging. 2014; 95: 289-300.
42. Wild D, Bomanji JB, Benkert P, Maecke H, Ell PJ, Reubi JC, et al. Comparison of 68Ga-DOTANOC and 68Ga-DOTATATE PET/CT within patients with gastroenteropancreatic neuroendocrine tumors. J Nucl Med. 2013; 54: 364-72.

43. Yang J, Kan Y, Ge BH, Yuan L, Li C, Zhao W. Diagnostic role of Gallium-68 DOTATOC and Gallium-68 DOTATATE PET in patients with neuroendocrine tumors: a meta-analysis. Acta Radiol. 2014; 55: 389-98.

44. Treglia G, Castaldi P, Rindi G, Giordano A, Rufini V. Diagnostic performance of Gallium-68 somatostatin receptor PET and PET/CT in patients with thoracic and gastroenteropancreatic neuroendocrine tumours: a meta-analysis. Endocrine. 2012; 42: 80-7.

45. Ambrosini V, Campana D, Bodei L, Nanni C, Castellucci P, Allegri V, et al. 68Ga-DOTANOC PET/CT clinical impact in patients with neuroendocrine tumors. J Nucl Med. 2010; 51: 669-73.

46. Frilling A, Sotiropoulos GC, Radtke A, Malago M, Bockisch A, Kuehl H, et al. The impact of $68 \mathrm{Ga}$-DOTATOC positron emission tomography/computed tomography on the multimodal management of patients with neuroendocrine tumors. Ann Surg. 2010; 252: 850-6.

47. Binderup T, Knigge U, Loft A, Federspiel B, Kjaer A. 18F-fluorodeoxyglucose positron emission tomography predicts survival of patients with neuroendocrine tumors. Clin Cancer Res. 2010; 16: 978-85.

48. Bahri H, Laurence L, Edeline J, Leghzali H, Devillers A, Raoul JL, et al. High prognostic value of 18F-FDG PET for metastatic gastroenteropancreatic neuroendocrine tumors: a long-term evaluation. J Nucl Med. 2014; 55: 1786-90.

49. Ilhan $\mathrm{H}$, Fendler WP, Cyran CC, Spitzweg C, Auernhammer CJ, Gildehaus FJ, et al. Impact of (68)Ga-DOTATATE PET/CT on the surgical management of primary neuroendocrine tumors of the pancreas or ileum. Ann Surg Oncol. 2015; 22: 164-71.

50. Campana D, Ambrosini V, Pezzilli R, Fanti S, Labate AM, Santini D, et al. Standardized uptake values of (68)Ga-DOTANOC PET: a promising prognostic tool in neuroendocrine tumors. J Nucl Med. 2010; 51: 353-9.

51. Delpassand ES, Ranganathan D, Wagh N, Shafie A, Gaber A, Abbasi A, et al. (64)Cu-DOTATATE PET/CT for Imaging Patients with Known or Suspected Somatostatin Receptor-Positive Neuroendocrine Tumors: Results of the First U.S. Prospective, Reader-Masked Clinical Trial. J Nucl Med. 2020; 61: 890-6

52. Ghobrial SN, Menda Y, Zamba GK, Mott SL, Gaimari-Varner K, Dick D, et al. Prospective Analysis of the Impact of 68Ga-DOTATOC Positron Emission Tomography-Computerized Axial Tomography on Management of Pancreatic and Small Bowel Neuroendocrine Tumors. Pancreas. 2020; 49: 1033-6.

53. Abongwa C, Mott S, Schafer B, McNeely P, Abusin G, O'Dorisio T, et al. Safety and accuracy of (68)Ga-DOTATOC PET/CT in children and young adults with solid tumors. Am J Nucl Med Mol Imaging. 2017; 7: 228-35.

54. Bodei L, Cremonesi M, Grana C, Rocca P, Bartolomei M, Chinol M, et al. Receptor radionuclide therapy with 90Y-[DOTA]0-Tyr3-octreotide (90Y-DOTATOC) in neuroendocrine tumours. Eur J Nucl Med Mol Imaging. 2004: $31: 1038-46$

55. Kwekkeboom DJ, Mueller-Brand J, Paganelli G, Anthony LB, Pauwels S, Kvols LK, et al. Overview of results of peptide receptor radionuclide therapy with 3 radiolabeled somatostatin analogs. J Nucl Med. 2005; 46 Suppl 1: 62S-6S.

56. Brans B, Bodei L, Giammarile F, Linden O, Luster M, Oyen WJG, et al. Clinical radionuclide therapy dosimetry: the quest for the "Holy Gray". Eur J Nucl Med Mol Imaging. 2007; 34: 772-86.

57. Ezziddin $\mathrm{S}$, Attassi $\mathrm{M}$, Yong-Hing $\mathrm{CJ}$, Ahmadzadehfar $\mathrm{H}$, Willinek $\mathrm{W}$, Grunwald F, et al. Predictors of long-term outcome in patients with well-differentiated gastroenteropancreatic neuroendocrine tumors after peptide receptor radionuclide therapy with 177Lu-octreotate. J Nucl Med. 2014; 55: 183-90.

58. Bodei L, Kidd M, Paganelli G, Grana CM, Drozdov I, Cremonesi M, et al. Long-term tolerability of PRRT in 807 patients with neuroendocrine tumours: the value and limitations of clinical factors. Eur J Nucl Med Mol Imaging. 2015; 42: 5-19.

59. Strosberg J, El-Haddad G, Wolin E, Hendifar A, Yao J, Chasen B, et al. Phase 3 Trial of (177)Lu-Dotatate for Midgut Neuroendocrine Tumors. N Engl J Med. 2017; 376: 125-35.

60. Kratochwil C, Giesel FL, Bruchertseifer F, Mier W, Apostolidis C, Boll R, et al. (2)(1)(3)Bi-DOTATOC receptor-targeted alpha-radionuclide therapy induces remission in neuroendocrine tumours refractory to beta radiation: a first-in-human experience. Eur J Nucl Med Mol Imaging. 2014; 41: 2106-19.

61. Ginj M, Zhang H, Waser B, Cescato R, Wild D, Wang X, et al. Radiolabeled somatostatin receptor antagonists are preferable to agonists for in vivo peptide receptor targeting of tumors. Proc Natl Acad Sci U S A. 2006; 103: 16436-41.

62. Wild D, Fani M, Behe M, Brink I, Rivier JE, Reubi JC, et al. First clinical evidence that imaging with somatostatin receptor antagonists is feasible. J Nucl Med. 2011; 52: 1412-7.

63. Evans JC, Malhotra M, Cryan JF, O'Driscoll CM. The therapeutic and diagnostic potential of the prostate specific membrane antigen/glutamate carboxypeptidase II (PSMA/GCPII) in cancer and neurological disease. Br J Pharmacol. 2016; 173: 3041-79.

64. Sathekge M, Lengana T, Modiselle M, Vorster M, Zeevaart J, Maes A, et al. (68)Ga-PSMA-HBED-CC PET imaging in breast carcinoma patients. Eur J Nucl Med Mol Imaging. 2017; 44: 689-94.

65. Rhee H, Blazak J, Tham CM, Ng KL, Shepherd B, Lawson M, et al. Pilot study: use of gallium-68 PSMA PET for detection of metastatic lesions in patients with renal tumour. EJNMMI Res. 2016; 6: 76 . 
66. Ross JS, Sheehan CE, Fisher HA, Kaufman RP, Jr., Kaur P, Gray K, et al. Correlation of primary tumor prostate-specific membrane antigen expression with disease recurrence in prostate cancer. Clin Cancer Res. 2003; 9: 6357-62.

67. Rauscher I, Maurer T, Fendler WP, Sommer WH, Schwaiger M, Eiber M. (68)Ga-PSMA ligand PET/CT in patients with prostate cancer: How we review and report. Cancer Imaging. 2016; 16: 14.

68. Hofman MS, Lawrentschuk N, Francis RJ, Tang C, Vela I, Thomas P, et al. Prostate-specific membrane antigen PET-CT in patients with high-risk prostate cancer before curative-intent surgery or radiotherapy (proPSMA): a prospective, randomised, multicentre study. Lancet. 2020; 395: 1208-16.

69. Ekmekcioglu O, Busstra M, Klass ND, Verzijlbergen F. Bridging the Imaging Gap: PSMA PET/CT Has a High Impact on Treatment Planning in Prostate Cancer Patients with Biochemical Recurrence-A Narrative Review of the Literature. J Nucl Med. 2019; 60: 1394-8.

70. Administration FaD. FDA approves second PSMA-targeted PET imaging drug for men with prostate cancer. Food and Drug Administration website. 2021.

71. Benesova M, Schafer M, Bauder-Wust U, Afshar-Oromieh A, Kratochwil C, Mier W, et al. Preclinical Evaluation of a Tailor-Made DOTA-Conjugated PSMA Inhibitor with Optimized Linker Moiety for Imaging and Endoradiotherapy of Prostate Cancer. J Nucl Med. 2015; 56: 914-20.

72. Kratochwil C, Giesel FL, Stefanova M, Benesova M, Bronzel $M$, Afshar-Oromieh A, et al. PSMA-Targeted Radionuclide Therapy of Metastatic Castration-Resistant Prostate Cancer with 177Lu-Labeled PSMA-617. J Nucl Med. 2016; 57: 1170-6.

73. Baum RP, Kulkarni HR, Schuchardt C, Singh A, Wirtz M, Wiessalla S, et al. 177Lu-Labeled Prostate-Specific Membrane Antigen Radioligand Therapy of Metastatic Castration-Resistant Prostate Cancer: Safety and Efficacy. J Nucl Med. 2016; 57: 1006-13

74. Fendler WP, Rahbar K, Herrmann K, Kratochwil C, Eiber M. (177)Lu-PSMA Radioligand Therapy for Prostate Cancer. J Nucl Med. 2017; 58: 1196-200.

75. Hofman MS, Violet J, Hicks RJ, Sandhu S. [(177)Lu]-PSMA-617 radionuclide therapy in patients with metastatic castration-resistant prostate cancer Author's reply. Lancet Oncol. 2018; 19: e373.

76. Ahmadzadehfar H, Eppard E, Kurpig S, Fimmers R, Yordanova A, Schlenkhoff $C D$, et al. Therapeutic response and side effects of repeated radioligand therapy with 177Lu-PSMA-DKFZ-617 of castrate-resistant metastatic prostate cancer. Oncotarget. 2016; 7: 12477-88.

77. Hofman MS, Emmett L, Sandhu S, Iravani A, Joshua AM, Goh JC, et al. [(177)Lu]Lu-PSMA-617 versus cabazitaxel in patients with metastatic castration-resistant prostate cancer (TheraP): a randomised, open-label, phase 2 trial. Lancet. 2021; 397: 797-804.

78. Michael J. Morris JSDB, Kim N. Chi, Karim Fizazi, Ken Herrmann, Kambiz Rahbar, Scott T. Tagawa, Luke T. Nordquist, Nitin Vaushampayan, Ghassan El-Haddad, Chandler H. Park, Tomasz M. Beer, Wendy J Pérez-Contreras, Michelle Desilvio, Euloge E. Kpamegan, Germo Gericke, Richard Adam Messmann, Bernd J. Krause, A. Oliver Sartor. Phase III study of lutetium-177-PSMA-617 in patients with metastatic castration-resistant prostate cancer (VISION). Journal of Clinical Oncology. 2021; 39.

79. Kratochwil C, Bruchertseifer F, Giesel FL, Weis M, Verburg FA, Mottaghy F, et al. 225Ac-PSMA-617 for PSMA-Targeted alpha-Radiation Therapy of Metastatic Castration-Resistant Prostate Cancer. J Nucl Med. 2016; 57: 1941-4.

80. Sathekge M, Bruchertseifer F, Vorster M, Lawal IO, Knoesen O, Mahapane J, et al. Predictors of Overall and Disease-Free Survival in Metastatic Castration-Resistant Prostate Cancer Patients Receiving (225)Ac-PSMA-617 Radioligand Therapy. J Nucl Med. 2020; 61: 62-9.

81. Kratochwil C, Bruchertseifer F, Rathke H, Hohenfellner M, Giesel FL, Haberkorn U, et al. Targeted alpha-Therapy of Metastatic Castration-Resistant Prostate Cancer with (225)Ac-PSMA-617: Swimmer-Plot Analysis Suggests Efficacy Regarding Duration of Tumor Control. J Nucl Med. 2018; 59: 795-802

82. Markwalder R, Reubi JC. Gastrin-releasing peptide receptors in the human prostate: relation to neoplastic transformation. Cancer Res. 1999; 59: 1152-9.

83. Kahkonen E, Jambor I, Kemppainen J, Lehtio K, Gronroos TJ, Kuisma A, et al. In vivo imaging of prostate cancer using [68Ga]-labeled bombesin analog BAY86-7548. Clin Cancer Res. 2013; 19: 5434-43.

84. Touijer KA, Michaud L, Alvarez HAV, Gopalan A, Kossatz S, Gonen M, et al. Prospective Study of the Radiolabeled GRPR Antagonist BAY86-7548 for Positron Emission Tomography/Computed Tomography Imaging of Newly Diagnosed Prostate Cancer. Eur Urol Oncol. 2019; 2: 166-73.

85. Minamimoto $R$, Hancock S, Schneider B, Chin FT, Jamali M, Loening A, et al. Pilot Comparison of (6)(8)Ga-RM2 PET and (6)(8)Ga-PSMA-11 PET in Patients with Biochemically Recurrent Prostate Cancer. J Nucl Med. 2016; 57: 557-62.

86. Minamimoto R, Sonni I, Hancock S, Vasanawala S, Loening A, Gambhir SS, et al. Prospective Evaluation of (68)Ga-RM2 PET/MRI in Patients with Biochemical Recurrence of Prostate Cancer and Negative Findings on Conventional Imaging. J Nucl Med. 2018; 59: 803-8.

87. Schroeder RP, de Visser $M$, van Weerden WM, de Ridder CM, Reneman $\mathrm{S}$, Melis $M$, et al. Androgen-regulated gastrin-releasing peptide receptor expression in androgen-dependent human prostate tumor xenografts. Int J Cancer. 2010; 126: 2826-34.

88. Kurth J, Krause BJ, Schwarzenbock SM, Bergner C, Hakenberg OW, Heuschkel M. First-in-human dosimetry of gastrin-releasing peptide receptor antagonist [(177)Lu]Lu-RM2: a radiopharmaceutical for the treatment of metastatic castration-resistant prostate cancer. Eur J Nucl Med Mol Imaging. 2020; 47: $123-35$
89. Ahmadzadehfar $\mathrm{H}$, Essler $\mathrm{M}$, Rahbar $\mathrm{K}$, Afshar-Oromieh A. Radionuclide Therapy for Bone Metastases: Utility of Scintigraphy and PET Imaging for Treatment Planning. PET Clin. 2018; 13: 491-503.

90. Dafermou A, Colamussi P, Giganti M, Cittanti C, Bestagno M, Piffanelli A. A multicentre observational study of radionuclide therapy in patients with painful bone metastases of prostate cancer. Eur J Nucl Med. 2001; 28: 788-98.

91. Lewington VJ. Bone-seeking radionuclides for therapy. J Nucl Med. 2005; 46 Suppl 1: 38S-47S

92. Sciuto R, Tofani A, Festa A, Giannarelli D, Pasqualoni R, Maini CL. Short- and long-term effects of 186Re-1,1-hydroxyethylidene diphosphonate in the treatment of painful bone metastases. I Nucl Med. 2000; 41: 647-54.

93. Palmedo H, Manka-Waluch A, Albers P, Schmidt-Wolf IG, Reinhardt M, Ezziddin S, et al. Repeated bone-targeted therapy for hormone-refractory prostate carcinoma: tandomized phase II trial with the new, high-energy radiopharmaceutical rhenium-188 hydroxyethylidenediphosphonate. J Clin Oncol. 2003; 21: 2869-75.

94. Biersack HJ, Palmedo H, Andris A, Rogenhofer S, Knapp FF, Guhlke S, et al. Palliation and survival after repeated (188)Re-HEDP therapy of hormone-refractory bone metastases of prostate cancer: a retrospective analysis. J Nucl Med. 2011; 52: 1721-6.

95. Kolesnikov-Gauthier H, Lemoine N, Tresch-Bruneel E, Olivier A, Oudoux A, Penel N. Efficacy and safety of (153)Sm-EDTMP as treatment of painful bone metastasis: a large single-center study. Support Care Cancer. 2018; 26: 751-8.

96. Sartor O, Reid RH, Hoskin PI, Quick DP, Ell PJ, Coleman RE, et al. Samarium-153-Lexidronam complex for treatment of painful bone metastases in hormone-refractory prostate cancer. Urology. 2004; 63: 940-5.

97. Ayati N, Aryana K, Jalilian A, Hoseinnejad T, Samani AB, Ayati Z, et al. Treatment efficacy of (153)Sm-EDTMP for painful bone metastasis. Asia Ocean J Nucl Med Biol. 2013; 1: 27-31.

98. Cheetham PJ, Petrylak DP. Alpha particles as radiopharmaceuticals in the treatment of bone metastases: mechanism of action of radium-223 chloride (Alpharadin) and radiation protection. Oncology (Williston Park). 2012; 26: 330-7, 41.

99. Parker C, Nilsson S, Heinrich D, Helle SI, O'Sullivan JM, Fossa SD, et al. Alpha emitter radium-223 and survival in metastatic prostate cancer. N Engl J Med. 2013; 369: 213-23

100. Saad F, Carles J, Gillessen S, Heidenreich A, Heinrich D, Gratt J, et al. Radium-223 and concomitant therapies in patients with metastatic castration-resistant prostate cancer: an international, early access, open-label, single-arm phase 3b trial. Lancet Oncol. 2016; 17: 1306-16.

101. Sartor O, Heinrich D, Mariados N, Mendez Vidal MJ, Keizman D, Thellenberg Karlsson C, et al. Re-treatment with radium-223: 2-year follow-up from an international, open-label, phase $1 / 2$ study in patients with castration-resistant prostate cancer and bone metastases. Prostate. 2019; 79: 1683-91.

102. Ueno NT, Tahara RK, Fujii T, Reuben JM, Gao H, Saigal B, et al. Phase II study of Radium-223 dichloride combined with hormonal therapy for hormone receptor-positive, bone-dominant metastatic breast cancer. Cancer Med. 2020; 9. $1025-32$

103. Subbiah V, Anderson PM, Kairemo K, Hess K, Huh WW, Ravi V, et al. Alpha Particle Radium 223 Dichloride in High-risk Osteosarcoma: A Phase I Dose Escalation Trial. Clin Cancer Res. 2019; 25: 3802-10.

104. Maris JM. Recent advances in neuroblastoma. N Engl J Med. 2010; 362: 2202-11.

105. Whittle SB, Smith V, Doherty E, Zhao S, McCarty S, Zage PE. Overview and recent advances in the treatment of neuroblastoma. Expert Rev Anticancer Ther. 2017; 17: 369-86.

106. de Kraker J, Hoefnagel KA, Verschuur AC, van Eck B, van Santen HM, Caron $\mathrm{HN}$. Iodine-131-metaiodobenzylguanidine as initial induction therapy in stage 4 neuroblastoma patients over 1 year of age. Eur J Cancer. 2008; 44: 551-6.

107. Alexander N, Vali R, Ahmadzadehfar H, Shammas A, Baruchel S. Review: The Role of Radiolabeled DOTA-Conjugated Peptides for Imaging and Treatment of Childhood Neuroblastoma. Curr Radiopharm. 2018; 11: 14-21.

108. Lowery AJ, Walsh S, McDermott EW, Prichard RS. Molecular and therapeutic advances in the diagnosis and management of malignant pheochromocytomas and paragangliomas. Oncologist. 2013; 18: 391-407.

109. Carlin S, Mairs RJ, McCluskey AG, Tweddle DA, Sprigg A, Estlin C, et al. Development of a real-time polymerase chain reaction assay for prediction of the uptake of meta-[(131)I]iodobenzylguanidine by neuroblastoma tumors. Clin Cancer Res. 2003; 9: 3338-44.

110. Tan TH, Hussein Z, Saad FF, Shuaib IL. Diagnostic Performance of (68)Ga-DOTATATE PET/CT, (18)F-FDG PET/CT and (131)I-MIBG Scintigraphy in Mapping Metastatic Pheochromocytoma and Paraganglioma. Nucl Med Mol Imaging. 2015; 49: 143-51.

111. Pryma DA, Chin BB, Noto RB, Dillon JS, Perkins S, Solnes L, et al. Efficacy and Safety of High-Specific-Activity (131)I-MIBG Therapy in Patients with Advanced Pheochromocytoma or Paraganglioma. J Nucl Med. 2019; 60: 623-30.

112. Fonte JS, Robles JF, Chen CC, Reynolds J, Whatley M, Ling A, et al. False-negative (1)(2)(3)I-MIBG SPECT is most commonly found in SDHB-related pheochromocytoma or paraganglioma with high frequency to develop metastatic disease. Endocr Relat Cancer. 2012; 19: 83-93.

113. Wilson JS, Gains JE, Moroz V, Wheatley K, Gaze MN. A systematic review of 131I-meta iodobenzylguanidine molecular radiotherapy for neuroblastoma. Eur J Cancer. 2014; 50: 801-15. 
114. Matthay KK, Yanik G, Messina J, Quach A, Huberty J, Cheng SC, et al. Phase II study on the effect of disease sites, age, and prior therapy on response to iodine-131-metaiodobenzylguanidine therapy in refractory neuroblastoma. J Clin Oncol. 2007; 25: 1054-60.

115. Chang CA, Pattison DA, Tothill RW, Kong G, Akhurst TJ, Hicks RJ, et al. (68)Ga-DOTATATE and (18)F-FDG PET/CT in Paraganglioma and Pheochromocytoma: utility, patterns and heterogeneity. Cancer Imaging. 2016; 16: 22.

116. Han S, Suh CH, Woo S, Kim YJ, Lee JJ. Performance of (68)Ga-DOTA-Conjugated Somatostatin Receptor-Targeting Peptide PET in Detection of Pheochromocytoma and Paraganglioma: A Systematic Review and Metaanalysis. J Nucl Med. 2019; 60: 369-76.

117. Scanlan MJ, Raj BK, Calvo B, Garin-Chesa P, Sanz-Moncasi MP, Healey JH, et al. Molecular cloning of fibroblast activation protein alpha, a member of the serine protease family selectively expressed in stromal fibroblasts of epithelial cancers. Proc Natl Acad Sci U S A. 1994; 91: 5657-61.

118. Zi F, He J, He D, Li Y, Yang L, Cai Z. Fibroblast activation protein alpha in tumor microenvironment: recent progression and implications (review). Mol Med Rep. 2015; 11: 3203-11.

119. Jacob M, Chang L, Pure E. Fibroblast activation protein in remodeling tissues. Curr Mol Med. 2012; 12: 1220-43.

120. Kratochwil C, Flechsig P, Lindner T, Abderrahim L, Altmann A, Mier W, et al. (68)Ga-FAPI PET/CT: Tracer Uptake in 28 Different Kinds of Cancer. J Nucl Med. 2019; 60: 801-5.

121. Watabe T, Liu Y, Kaneda-Nakashima K, Shirakami Y, Lindner T, Ooe K, et al. Theranostics Targeting Fibroblast Activation Protein in the Tumor Stroma: (64) Cu- and (225)Ac-Labeled FAPI-04 in Pancreatic Cancer Xenograft Mouse Models. J Nucl Med. 2020; 61: 563-9.

122. Lindner T, Loktev A, Altmann A, Giesel F, Kratochwil C, Debus J, et al. Development of Quinoline-Based Theranostic Ligands for the Targeting of Fibroblast Activation Protein. J Nucl Med. 2018; 59: 1415-22.

123. Baum RP, Singh A, Schuchardt C, Kulkarni HR, Klette I, Wiessalla S, et al. (177)Lu-3BP-227 for Neurotensin Receptor 1-Targeted Therapy of Metastatic Pancreatic Adenocarcinoma: First Clinical Results. J Nucl Med. 2018; 59: 809-14.

124. Mousavi A. CXCL12/CXCR4 signal transduction in diseases and its molecular approaches in targeted-therapy. Immunol Lett. 2020; 217: 91-115.

125. Herrmann K, Schottelius M, Lapa C, Osl T, Poschenrieder A, Hanscheid H, et al. First-in-Human Experience of CXCR4-Directed Endoradiotherapy with 177Lu- and 90Y-Labeled Pentixather in Advanced-Stage Multiple Myeloma with Extensive Intra- and Extramedullary Disease. J Nucl Med. 2016; 57: $248-51$.

126. Kaminski MS, Zelenetz AD, Press OW, Saleh M, Leonard J, Fehrenbacher L, et al. Pivotal study of iodine I 131 tositumomab for chemotherapy-refractory low-grade or transformed low-grade B-cell non-Hodgkin's lymphomas. J Clin Oncol. 2001; 19: 3918-28

127. Witzig TE, Gordon LI, Cabanillas F, Czuczman MS, Emmanouilides C, Joyce $R$, et al. Randomized controlled trial of yttrium-90-labeled ibritumomab tiuxetan radioimmunotherapy versus rituximab immunotherapy for patients with relapsed or refractory low-grade, follicular, or transformed B-cell non-Hodgkin's lymphoma. J Clin Oncol. 2002; 20: 2453-63.

128. Kolstad A, Illidge T, Bolstad N, Spetalen S, Madsbu U, Stokke C, et al. Phase $1 / 2$ a study of $177 \mathrm{Lu}$-lilotomab satetraxetan in relapsed/refractory indolent non-Hodgkin lymphoma. Blood Adv. 2020; 4: 4091-101.

129. Rudisile S, Gosewisch A, Wenter V, Unterrainer M, Boning G, Gildehaus FJ, et al. Salvage PRRT with (177)Lu-DOTA-octreotate in extensively pretreated patients with metastatic neuroendocrine tumor (NET): dosimetry, toxicity, efficacy, and survival. BMC Cancer. 2019: 19: 788 . 